\title{
Active intermediation in a monetary overlapping generations economy ${ }^{1}$
}

\author{
Mark Pingle ${ }^{\mathrm{a}}$, Leigh Tesfatsion ${ }^{\mathrm{b}, *}$ \\ ${ }^{a}$ Department of Economics, University of Nevada, Reno, NV 89557, USA \\ ${ }^{\mathrm{b}}$ Department of Economics, Iowa State University, Ames, IA 50011-1070, USA
}

\begin{abstract}
This paper establishes that the profit-seeking activities of private intermediaries can ensure Pareto efficiency in the standard pure-exchange monetary overlapping generations economy without the need for government monetary or fiscal policy intervention. Moreover, these profit-seeking activities are shown to rule out all aperiodic and $k$ periodic cycles for $k$ greater than 2. Contrary to much recent work on intermediation, the profit opportunities that arise for intermediaries in this context are not due to assumed frictions or asymmetric information. Rather, they are due to the dynamic open-ended structure of the economy, which permits debt roll-over. (C) 1998 Elsevier Science B.V. All rights reserved.
\end{abstract}

JEL classification: D61; E44; G23

Keywords: Financial intermediation; Overlapping generations; Pareto efficiency

\section{Introduction}

The conventional definition of a competitive equilibrium does not ensure a Pareto efficient outcome for the overlapping generations economy (Gale, 1973; Samuelson, 1958). This well-known finding has widely been interpreted to mean that, in the absence of altruistic preferences (Barro, 1974) or a productive

\footnotetext{
*Corresponding author. E-mail: tesfatsi@iastate.edu

${ }^{1}$ This paper is a revised abbreviated version of Pingle and Tesfatsion (1996). The authors are grateful to J. Duffy, H. Quirmbach, the editor, and an anonymous referee for helpful comments.
} 
nonreproducible asset such as land (McCallum, 1987), some form of government intervention is essential to ensure Pareto efficiency for overlapping generations economies. See, for example, Azariadis (1993, pp. 270-271) and Champ and Freeman (1994, pp. 206-207).

In Pingle and Tesfatsion (1991) we question whether the conventional definition of a competitive equilibrium, as applied to an overlapping generations (OG) economy, is truly satisfactory. The conventional definition was developed for a standard Walrasian economy with a finite number of consumers and goods whereas the OG economy necessarily contains an infinite number of consumers and goods. As noted by Shell (1971), the presence of this double infinity in OG economies introduces a new trading opportunity, namely, the possibility of incurring and rolling over a debt forever as time proceeds into the infinite future. The problem with applying the conventional equilibrium definition to the $\mathrm{OG}$ economy is that it does not contain any conditions that recognize this new trading opportunity. Rather, private agents are assumed to focus narrowly on consumption and production opportunities, ignoring possible profit opportunities arising from debt issue and roll over. Is it really surprising, then, that outcomes in OG economies can fail to be Pareto efficient in the absence of government intervention?

Using the Samuelson (1958) OG economy as an illustration, we show in Pingle and Tesfatsion (1991) that the introduction of a private, profit-driven, price-taking intermediary that is willing and able to arbitrage profit opportunities associated with debt issue can have a dramatic impact on the efficiency properties of the economy. For example, regardless of the precise form assumed for the profit objective of the intermediary, Pareto inefficient outcomes are ruled out as equilibria since the intermediary necessarily perceives unbounded profit opportunities.

Extending this prior work, the current paper introduces a private profitdriven price-setting corporation into the basic monetary OG economy studied by Grandmont and Laroque (1973), Balasko and Shell (1981), and Grandmont (1985), among others. The corporation issues unsecured debt in the form of stock shares. In the initial period the corporation announces its current and future stock share prices and expected dividend payments in an attempt to maximize its market value in accordance with the interests of its successive shareholders. The conventional definition of a monetary equilibrium is generalized to include this corporate objective.

We stress our corporate intermediary is a private sector institution, not a government or government-like institution. As a price setter, the corporation is fundamentally different from the other private-sector agents in the model, i.e., the price-taking consumers. However, the corporation's price-setting power does not make it a government. Our corporation uses its price-setting power to make a market for its corporate stock shares. If the corporation were able to choose both the price and the quantity of the shares it traded, then it would 
indeed be a government-like agent with extraordinary powers. However, our corporation's problem is not unlike that of many real-world intermediaries: Find a set of prices that will attract customers while generating a positive rate of return. Competing for the consumers' dollars are other goods whose prices are determined by the usual competitive market clearing conditions. In addition, consumers can choose to hold money for use at a later time.

We find that efficiency is generated as the corporation adjusts the prices it sets for its shares in pursuit of higher rates of return for its shareholders. More precisely, we first derive a necessary and sufficient condition for an allocation for our 'Corporate Economy' to be Pareto efficient. We then establish that all equilibrium allocations for the Corporate Economy are Pareto efficient. Moreover, the equilibrium set is nonempty. In particular, we show that the corporation plays a meaningful role in the economy - issuing positively priced unsecured debt and earning a windfall return - whenever the value of the initial real money balances held by consumers fails to equal the particular value needed to support the Pareto efficient golden rule equilibrium. We further show that a first welfare theorem and existence theorem are obtained both in the presence and in the absence of gross substitutability if the offer curve of each consumer satisfies certain curvature restrictions of the type studied by Grandmont (1985). Without these curvature restrictions, the corporation faces an interesting time-inconsistency problem.

We also investigate the dynamic properties of Corporate Economy equilibria. Given gross substitutability, the golden rule consumption allocation is immediately obtained. In the absence of gross substitutability, only three types of dynamic behavior are possible in equilibrium: either (a) the economy enters immediately into a cycle with a period-2 orbit; or (b) the economy converges to a limit cycle with a period- 2 orbit; or (c) the economy converges in damped cyclical fashion to the golden rule consumption allocation. Consequently, although an endogenous 'business cycle' is possible for the Corporate Economy, the presence of a private profit-driven corporation rules out the existence of the more complex (and Pareto inefficient) periodic and aperiodic equilibria that are shown by Grandmont (1985) to arise in the basic monetary OG economy.

The work closest in spirit to our own is the seminal paper by E. Thompson (1967). Thompson asserts (p. 1205) that, if interest rates were forever too low for Pareto efficiency, then private firms would proceed to bid up interest rates by issuing new debt to finance current new expenditures. By explicitly introducing such firms into the standard OG economy, we obtain results which enable us to restate Thompson's important insight in a more general way: namely, like consumption and production, intermediation should be recognized as a fundamental economic activity of the private sector. Moreover, our results enable us to generalize the information-theoretic view of intermediation expressed in the research surveyed by Bhattacharya and Thakor (1993) by showing that 
intermediation can play a significant role in dynamic open-ended economies even in the absence of frictions or asymmetric information.

\section{Consumer optimization in the corporate economy}

The Corporate Economy is a pure exchange OG economy that begins in period 1 and extends into the infinite future. The economy's population growth rate is equal to zero, and each generation consists of one two-period lived consumer. The economy contains a single perishable consumable resource that provides consumers with utility. The resource available during period $t$ will be referred to as good $t$.

Consumers born in periods $t \geq 1$ are identical aside from time of birth. The 'generation $t$ ' consumer is born at the beginning of period $t$ and lives through the end of period $t+1$. Each generation $t$ consumer is endowed with $w^{y}>0$ units of good $t$ and $w^{\mathrm{o}}>0$ units of good $t+1$. Letting $c_{t}^{\mathrm{y}}$ and $c_{t+1}^{\mathrm{o}}$ denote the young- and old-age consumption levels of the generation $t$ consumer, it is assumed that his lifetime consumption preferences are measured by a utility function $U\left(c_{t}^{\mathrm{y}}, c_{t+1}^{\mathrm{o}}\right)$ that is twice continuously differentiable, strictly increasing, strictly quasi-concave, and satisfies $U\left(0, c_{t+1}^{\mathrm{o}}\right)=U\left(c_{t}^{\mathrm{y}}, 0\right)=U(0,0)$. Moreover, it will be assumed that the indifference curves generated by $U(\cdot)$ do not come arbitrarily close to being either kinked or linear, in the sense of Balasko and Shell (1980, Proposition 5.6, Properties $\mathrm{C}$ and $\mathrm{C}^{\prime}$ ). Finally, letting $U_{1}$ and $U_{2}$ denote the partial derivatives of the utility function with respect to $c_{t}^{y}$ and $c_{t+1}^{o}$, respectively, it is also assumed that

$$
\operatorname{MRS}\left(w^{\mathrm{y}}, w^{\mathrm{o}}\right) \equiv \frac{U_{1}\left(w^{\mathrm{y}}, w^{\mathrm{o}}\right)}{U_{2}\left(w^{\mathrm{y}}, w^{\mathrm{o}}\right)}<1 .
$$

The implications of these utility function regularity conditions will be clarified below.

Consumers can hold both government-issued fiat money and stock shares issued by a private corporation. Let $M_{t}$ denote the quantity of money held by the generation $t$ consumer from period $t$ to period $t+1$, and let $P_{t}$ denote the price of good $t$ in terms of fiat money. The generation $t$ consumer obtains the $M_{t}$ units of money by trading away $M_{t} / P_{t}$ units of the good $t$ endowment. In period $t+1$, the $M_{t}$ units of money can be used to purchase $M_{t} / P_{t+1}$ units of good $t+1$. Thus, as long as the prices $P_{t}$ and $P_{t+1}$ are not infinite, the generation $t$ consumer is able to transfer wealth from period $t$ to period $t+1$ by choosing to obtain and hold fiat money.

Let $\theta_{t}$ denote the number of stock shares purchased $\left(\theta_{t}>0\right)$ or sold short $\left(\theta_{t}<0\right)$ in period $t$ by the generation $t$ consumer, and let $v_{t}$ denote the price of a share in period $t$, measured in terms of good $t$. The consumer purchases or sells 
short the $\theta_{t}$ shares in return for $v_{t} \theta_{t}$ units of good $t$. In period $t+1$, the consumer then receives or pays out $\left[v_{t+1}+d_{t+1}^{\mathrm{e}}\right] \theta_{t}$ units of good $t+1$, where $d_{t+1}^{\mathrm{e}}$ denotes the expected per share dividend. Thus, in addition to saving through money holding, the generation $t$ consumer is able to save or borrow from period $t$ to period $t+1$ through share transactions.

Given these specifications, the lifetime utility maximization problem facing the generation $t$ consumer can be represented as

$$
\max U\left(c_{t}^{\mathrm{y}}, c_{t+1}^{\mathrm{o}}\right)
$$

with respect to $c_{t}^{\mathrm{y}}, c_{t+1}^{\mathrm{o}}, M_{t}$, and $\theta_{t}$ subject to the budget and nonnegativity constraints

$$
\begin{aligned}
& c_{t}^{\mathrm{y}}=w^{\mathrm{y}}-\left[M_{t} / P_{t}\right]-v_{t} \theta_{t}, \\
& c_{t+1}^{\mathrm{o}}=w^{\mathrm{o}}+\left[M_{t} / P_{t+1}\right]+\left[v_{t+1}+d_{t+1}^{\mathrm{e}}\right] \theta_{t}, \\
& 0 \leq c_{t}^{\mathrm{y}}, c_{t+1}^{\mathrm{o}}, M_{t} .
\end{aligned}
$$

The generation $t$ consumer takes as given the positive (possibly infinitely valued) goods prices $P_{t}$ and $P_{t+1}$, the finite nonnegative share prices $v_{t}$ and $v_{t+1}$, and the finite nonnegative expected per share dividend $d_{t+1}^{\mathrm{e}}$.

The regularity conditions on the utility function $U(\cdot)$ guarantee that each consumer in generation $t \geq 1$ will choose $c_{t}^{\mathrm{y}}>0$ and $c_{t+1}^{\mathrm{o}}>0$. Given $v_{t}>0$, the first-order conditions for problem (2) require that

$$
\operatorname{MRS}\left(c_{t}^{\mathrm{y}}, c_{t+1}^{\mathrm{o}}\right)=q_{t},
$$

where

$$
q_{t} \equiv \frac{v_{t+1}+d_{t+1}^{\mathrm{e}}}{v_{t}}
$$

denotes the expected rate of return on holding shares from period $t$ to $t+1$.

Let $s_{t} \equiv w^{y}-c_{t}^{y}$ denote the savings of the generation $t$ consumer. For later purposes, it will now be shown that the budget constraints for problem (2) can be simply expressed in terms of $s_{t}$ and the share rate of return $q_{t}$ over the range $0<q_{t}<+\infty$ whenever $v_{t}>0$. The proof of the following proposition (and all subsequent propositions) can be found in an appendix to this paper.

Proposition 2.1. Suppose $v_{t}>0$ and $0<q_{t}<+\infty$. Then a finite solution exists for problem (2) if and only if either $0 \leq P_{t} / P_{t+1} \leq q_{t}$ or $P_{t}$ and $P_{t+1}$ are both infinite. In either case the budget constraints for problem (2) can be expressed, without loss of generality, as

$$
\begin{aligned}
& c_{t}^{\mathrm{y}}=w^{\mathrm{y}}-s_{t}, \\
& c_{t+1}^{\mathrm{o}}=w^{\mathrm{o}}+q_{t} s_{t}, \\
& 0 \leq c_{t}^{\mathrm{y}}, c_{t+1}^{\mathrm{o}},
\end{aligned}
$$


and the optimal consumption and savings levels of the generation $t$ consumer are uniquely determined as functions $\left(c^{\mathrm{y}}\left(q_{t}\right), c^{\mathrm{o}}\left(q_{t}\right), s\left(q_{t}\right)\right)$ of the period $t$ share rate of return $q_{t}$, where $s\left(q_{t}\right) \geq 0$ if and only if $q_{t} \geq \operatorname{MRS}\left(w^{\mathrm{y}}, w^{\mathrm{o}}\right)$.

In the initial period 1 the Corporate Economy consists of one generation 1 young consumer and one generation 0 old consumer. The generation 0 old consumer is endowed with $w^{\mathrm{o}}$ units of good 1 and a positive amount $M_{0}$ of fiat money issued once and for all time by government. The generation 0 old consumer is the entrepreneur who starts the corporation, hence he is also endowed with an initial positive quantity of stock shares, $\theta_{0}$. To retain symmetry with other consumers, it is assumed that the generation 0 old consumer plans to sell these shares at the unit price $v_{1}$ and expects a per share dividend payment $d_{1}^{\mathrm{e}}$.

The utility of the generation 0 consumer in period 1 is assumed to increase with increases in his consumption level $c_{1}^{\mathrm{o}}$. Thus, the generation 0 old consumer chooses $c_{1}^{\text {o }}$ to satisfy

$$
c_{1}^{\mathrm{o}}=w^{\mathrm{o}}+\left[M_{0} / P_{1}\right]+\left[v_{1}+d_{1}^{\mathrm{e}}\right] \theta_{0} .
$$

Note from (8) that the introduction of fiat money and corporate stock shares gives the generation 0 old consumer a potential wealth windfall.

\section{The corporation}

A distinguishing feature of the corporate form of business is that a corporation can outlive any particular shareholder and generally has no foreseeable date of termination. As an approximation to this reality, we suppose that the corporation has an infinite planning horizon spanning all successive generations of its shareholders. Moreover, since the focus of the present study is on the ability of corporations to incur and roll over debt, we simplify the analysis by abstracting from the production process. That is, we assume that the corporation has no capital assets and employs no labor, and hence produces no physical output by which to generate earnings. Nonetheless, the corporation can borrow. As will be clarified, below, this permits in principle the continual pay-out of positive dividends financed by successive debt accumulation and roll-over, hence the shares of the corporation need not be valueless.

We assume that the corporation acts in the interests of its shareholders. Examining the budget constraints (5) and (6), note that the optimized lifetime utility of the generation $t$ consumer is an increasing function of $q_{t}$, the expected rate of return on holding shares from period $t$ to period $t+1$, over the range $q_{t} \geq \operatorname{MRS}\left(w^{\mathrm{y}}, w^{\mathrm{o}}\right)$ where the consumer's optimal savings level $s\left(q_{t}\right)$ is nonnegative. Examining the budget constraint (8), note that the utility of the generation 0 consumer is an increasing function of $\left[v_{1}+d_{1}^{\mathrm{e}}\right] \theta_{0}$, his expected windfall return from stock share ownership. To what extent can the corporation control these quantities? 
By definition (4), the expected share rate of return $q_{t}$ depends upon the share prices $v_{t}$ and $v_{t+1}$ and the expected dividend $d_{t+1}^{\mathrm{e}}$. It follows that the corporation's control over $q_{t}$ depends upon its control over share prices and expected dividends. In reality, corporations can and do influence their stock share prices by buying and selling their own shares. Here it is assumed that the corporation actually sets its own share prices by agreeing to buy or sell any quantity of shares at the share prices it desires to support.

In particular, at the beginning of period 1 the corporation announces a sequence $\boldsymbol{v}=\left(v_{1}, v_{2}, \ldots\right)$ of finite nonnegative share prices $v_{t}$ together with a sequence $\boldsymbol{d}^{\mathrm{e}}=\left(d_{1}^{\mathrm{e}}, d_{2}^{\mathrm{e}}, \ldots\right)$ of finite nonnegative expected dividend payments $d_{t}^{\mathrm{e}}$. In announcing this pair of sequences $\boldsymbol{I}=\left(\boldsymbol{v}, \boldsymbol{d}^{\mathrm{e}}\right)$, henceforth referred to as a prospectus, the corporation takes nominal goods prices as given. It is assumed that the announced prospectus is known to all current and potential shareholders. Although the dividend expectations of shareholders can differ in principle from the dividend expectations of the corporation as embodied in its prospectus, the definition of an equilibrium given below in Section 5 will follow the usual convention in assuming that these expectations coincide. Without loss of generality, then, we simplify the exposition below by using the same notation to represent these expectations.

The corporation desires to exist indefinitely, implying that it must be concerned both with the feasibility of its prospectus and with the optimality of its prospectus as perceived by potential shareholders. We begin by characterizing the subset of prospectuses perceived by the corporation to be viable. We then explain how the corporation winnows down this subset lexicographically, in the interests of its successive shareholders, in order to obtain an optimal choice set for selection of a prospectus in the initial period 1 .

The corporation only considers prospectuses that it expects to be able to support. Since the corporation has no physical assets and no earnings capacity from physical production, the shares that it issues represent unsecured debt. The quantity $v_{1} \theta_{0}$ measures the value of corporate debt which matures in period 1 . The only way that the corporation can repay this debt is by rolling it over. In order for the corporation to remain solvent, the value of debt that it issues in period $1, v_{1} \theta_{1}$, must be at least as great as the debt maturing in period $1, v_{1} \theta_{0}$. More generally, the incremental change in the value of corporate shares outstanding in any period $t \geq 1$, measured in terms of good $t$, is given by

$$
\pi_{t} \equiv v_{t}\left[\theta_{t}-\theta_{t-1}\right]
$$

the net earnings of the corporation in period $t$. It follows by a simple induction argument that the corporation is solvent in period $t$ only if $\pi_{t} \geq 0$.

If $\pi_{t}>0$, i.e., if $\theta_{t}>\theta_{t-1}$, the corporation is issuing new shares in period $t$ to cover an increase in the demand for its shares. In this case the corporation has positive net earnings in period $t$ equal to $\pi_{t}$ units of good $t$. Because good $t$ is perishable, any net earnings held by the corporation become worthless at the 
end of the period. It is therefore assumed that the corporation pays out all net earnings in the form of dividends to its shareholders. Letting $d_{t}$ denote the good $t$ dividend per share paid to the (old aged) shareholder in period $t$, who holds $\theta_{t-1}$ shares, it follows that

$$
\pi_{t}=d_{t} \theta_{t-1} \text {. }
$$

From an empirical standpoint, the corporation modeled here is an extreme case in that all of its dividends are financed by incurring new debt. However, many corporations do occasionally borrow to support a dividend distribution when earnings are low. In 1989, for example, Kane (1989, p. 36) argued that 'zombie firms...constitute roughly 25 percent of the FSLIC-insured thrift industry,' where a zombie thrift is a thrift with zero enterprise-contributed capital that must rely on FSLIC guarantees to keep attracting new deposits to pay off previous debts. Our model is an abstraction that allows us to focus on the efficiency and stability implications of debt roll over. The possible need for guarantees to ensure the viability of the corporation currently under consideration is taken up in Section 4.

In period 1 the corporation forms an estimate $\theta_{t}^{\mathrm{e}}=\theta_{t}(\boldsymbol{I}, \boldsymbol{P})$ for the quantity of shares $\theta_{t}$ that the corporation expects the generation $t$ consumer to demand, $t \geq 1$, conditional on a nominal goods price sequence $\boldsymbol{P}=\left(P_{1}, P_{2}, \ldots\right)$ and a prospectus $\boldsymbol{I}=\left(v, d^{\mathrm{e}}\right)$. The corporation's period $t$ expected net earnings are then given by

$$
\pi_{t}^{\mathrm{e}}=v_{t}\left[\theta_{t}^{\mathrm{e}}-\theta_{t-1}^{\mathrm{e}}\right],
$$

where $\theta_{0}^{\mathrm{e}} \equiv \theta_{0}$. Consequently, the dividend per share $d_{t}^{\mathrm{e}}$ that the corporation privately expects to distribute in period $t$ must satisfy

$$
d_{t}^{\mathrm{e}^{*}} \theta_{t-1}^{\mathrm{e}}=\pi_{t}^{\mathrm{e}}
$$

For concreteness, it is henceforth assumed that the corporation sets $d_{t}^{\mathrm{e}^{*}}=0$ if $\theta_{t-1}^{\mathrm{e}}=0$.

If the privately-expected dividend payments (12) were to differ from those announced in the prospectus $\boldsymbol{I}$, the corporation would be deliberately deceiving its potential shareholders. We assume that the corporation does not engage in this behavior. Rather, we assume that the corporation's publicly announced prospectus $I$ exhibits dividend consistency in the sense that the dividend sequence $\boldsymbol{d}^{\mathrm{e}}$ appearing in $\boldsymbol{I}$ coincides with the dividend sequence $\boldsymbol{d}^{\mathrm{e} *}$ privately anticipated by the corporation.

In forming its share demand estimates $\theta_{t}^{\mathrm{e}}$, the corporation takes into account certain general structural implications of the utility maximization problem (2). In particular, the corporation recognizes that (i) if the share price $v_{t}$ is positive, then the share demand $\theta_{t}$ for generation $t$ will be bounded above; (ii) if $v_{t}$ is zero and the expected per-share return $\left[v_{t+1}+d_{t+1}^{\mathrm{e}}\right]$ is positive, then the share demand $\theta_{t}$ will be infinitely large; and (iii) if $v_{t}$ is positive and $\left[v_{t+1}+d_{t+1}^{\mathrm{e}}\right]$ is 
zero, then the share demand $\theta_{t}$ will be infinitely negative. This corporate knowledge will be referred to as structural rationality. Finally, the corporation is also assumed to be aware that the total real resources $w^{y}+w^{\circ}$ available in the economy in each period $t$ constitute a bounded sequence, implying that the sequence of real share demands, $v_{t} \theta_{t}$, must also be bounded over time.

A prospectus will be said to be viable from the viewpoint of the corporation if it satisfies the following three properties: (i) it generates nonnegative expected net earnings in each period; (ii) it exhibits dividend consistency relative to the corporation's structurally rational share demand expectations; and (iii) it implies a bounded sequence of expected real share demands. The set of viable prospectuses is nonempty, for it always contains the null prospectus consisting of zero-valued share prices and zero-valued expected dividend payments. Moreover, using definition (9) for expected net earnings together with the assumed structural rationality of the corporation's share demand expectations, the following property can be shown to hold for any viable prospectus $\boldsymbol{I}$ : If $v_{t}$ is zero in any period $t \geq 1$, then $\boldsymbol{I}$ must be the null prospectus.

The corporation is assumed to limit its attention to the subset of viable prospectuses that are in accordance with the interests of its successive shareholders. As will now be detailed, this involves the lexicographic construction of a nested sequence $\left(I_{t}\right)$ of subsets of viable prospectuses $I_{t}$, where each $I_{t}$ is optimal for generation $t$ conditional on $I_{t-1}$.

The set $I_{0}$ is the (possibly empty) subset of viable prospectuses yielding the highest possible wealth windfall $\left[v_{1}+d_{1}^{\mathrm{e}}\right] \theta_{0}$ for the generation 0 old consumer. If $I_{0}$ is empty, it is assumed the corporation sets $I_{1}=I_{0}$. If $I_{0}$ is nonempty and the wealth windfall entailed by each prospectus in $I_{0}$ is positive, it follows by dividend consistency and the assumed positivity of $\theta_{0}$ that the share price $v_{1}$ for each of the prospectuses in $I_{0}$ must also be positive. In this case the share rate of return $q_{1}$ for generation 1 is well-defined, and the corporation is assumed to restrict its attention further to the (possibly empty) subset $I_{1}$ of viable prospectuses in $I_{0}$ for which $q_{1}$ is as large as possible. If, instead, $I_{0}$ is nonempty and each prospectus in $I_{0}$ entails a zero wealth windfall, then it follows by nonnegativity of $v_{1}$ and $d_{1}^{\mathrm{e}}$ and positivity of $\theta_{0}$ that the share price $v_{1}$ must be zero for each prospectus in $I_{0}$. As previously explained, viability then implies that $I_{0}$ is a singleton set containing only the null prospectus and hence cannot be further restricted for the benefit of future generations. In this case it is supposed that the corporation simply sets $I_{1}=I_{0}$.

Suppose, now, that the corporation has constructed $I_{t}$ for some $t \geq 1$. If $I_{t}$ is the empty set, it is assumed that the corporation simply sets $I_{t+1}=I_{t}$. If $I_{t}$ is nonempty but $v_{t}$ is zero for some (hence for all) prospectuses in $I_{t}$, then, as previously explained, $I_{t}$ must be a singleton set consisting of the null prospectus. In this case no further winnowing of $I_{t}$ for the benefit of future generations is possible, and it is assumed that the corporation again sets $I_{t+1}=I_{t}$. 
To complete the inductive construction of $I_{t+1}$, it remains to show how the corporation constructs $I_{t+1}$ when $I_{t}$ is nonempty and $v_{t}$ is positive for each prospectus in $I_{t}$. In this case, by construction of $I_{t}, q_{t}$ is well defined and attains its largest possible value for each prospectus in $I_{t}$. This largest possible value must be positive; for, if not, then $v_{t+1}$ must be zero for each prospectus in $I_{t}$. As previously explained, $I_{t}$ would then have to be a singleton set containing only the null prospectus, a contradiction. A positive largest possible value for $q_{t}$ implies that $v_{t+1}$ must be positive, hence the share rate of return $q_{t+1}$ for generation $t+1$ is well-defined for each prospectus in $I_{t}$. The corporation is then assumed to further restrict its attention to the (possibly empty) subset $I_{t+1}$ of viable prospectuses in $I_{t}$ for which $q_{t+1}$ is as large as possible.

Let $\mathscr{I}(\boldsymbol{P})$ denote the (possibly empty) set of viable prospectuses that remains after all winnowing is complete, that is, let $\mathscr{I}(\boldsymbol{P})$ denote the intersection of the subsets $I_{t}$ for $t \geq 1$. The set $\mathscr{I}(\boldsymbol{P})$ then represents the corporation's optimal choice set for selection of a prospectus in period 1 . The corporation is assumed to be indifferent among all prospectuses in $\mathscr{I}(\boldsymbol{P})$.

The success of a modern corporation is often judged by the market value of its outstanding shares. The behavior of our corporation is consistent with this viewpoint. Given the definition (11) for expected net earnings, the definition (12) for the expected per share dividend, and dividend consistency, if follows that $d_{1}^{\mathrm{e}} \theta_{0}=v_{1}\left[\theta_{1}^{\mathrm{e}}-\theta_{0}\right]$ and hence $\left[v_{1}+d_{1}^{\mathrm{e}}\right] \theta_{0}=v_{1} \theta_{1}^{\mathrm{e}}$. This last relation shows that, by maximizing the expected windfall return $\left[v_{1}+d_{1}^{\mathrm{e}}\right] \theta_{0}$ to the generation 0 old consumer, the corporation also maximizes $v_{1} \theta_{1}^{\mathrm{e}}$, the expected market value of its outstanding shares at the end of period 1 . Furthermore, assuming $v_{t} \theta_{t}^{\mathrm{e}} \neq 0$, and using (12) and dividend consistency to eliminate $d_{t+1}^{e}$ from the expression (4) for $q_{t}$, one obtains

$$
q_{t}=\frac{v_{t+1} \theta_{t+1}^{\mathrm{e}}}{v_{t} \theta_{t}^{\mathrm{e}}}
$$

Consequently, by maximizing the expected share rate of return $q_{t}$ for the generation $t$ consumer, the corporation also maximizes the expected incremental increase in the market value of its shares from period $t$ to period $t+1$.

\section{Viability of the corporation}

The only way the corporation described in Section 3 can viably enhance the welfare of its shareholders is by incurring debt and rolling it over forever. Although $v_{t} \theta_{t}$ measures the market value of the corporation's stock shares during period $t$, it also measures the market value of the corporation's debt during period $t$. Thus, in attempting to increase the rate of return $q_{t}$ that the generation $t$ consumer receives for holding its shares, the corporation also 
increases the rate at which it assumes unsecured debt. This has led some to conclude that a privately owned firm such as the one described here is not viable. There are three basic arguments.

One argument, discussed by Lerner (1959, p. 523), is that such a firm operates as an illegal 'chain letter' or 'Ponzi scheme'. However, as Lerner also recognized, as long as the economy extends into the infinite future, no one need be hurt by the chain-letter aspect because correspondents need not run out. More precisely, our corporation can viably operate in an economy with an infinite time horizon as long as it attracts enough shareholders in each period $t$ to fund the obligations it incurs in period $t-1$.

The second argument is related to the corporation's negative net worth position. At the end of each period $t$, the corporation has no assets - all receipts are paid out in the form of either share redemptions or dividends - but it still has a liability equal to $v_{t} \theta_{t}$. Some researchers (e.g., Cass and Yaari, 1966, p. 360) have argued that any privately owned financial intermediary would shut down rather than operate with a negative net worth. However, the owners of a corporation - its shareholders - only care about net worth to the extent that it affects the total net returns (capital gains or losses plus dividend distributions) that are associated with holding shares in the corporation. Paradoxically, in our setting, a negative net worth position is actually necessary in order for the corporation to obtain positive total net returns for its shareholders in each period.

A third argument is that the corporation's survival might be threatened by the entry of other organizations that also seek to incur and roll over debt. In our context, the generation 0 old consumer who starts the corporation will likely receive a wealth windfall. However, this windfall can only be obtained if the generation 1 consumer can be persuaded to buy shares in the corporation. Suppose that the generation 1 consumer 'gets smart' and refuses to purchase shares in the corporation started by the generation 0 consumer, opting instead to start a similar corporation at the beginning of period 2. If successful, the generation 1 consumer would receive the wealth windfall rather than the generation 0 consumer. Of course, the generation 1 consumer would face the same problem that the generation 0 consumer faced. Thus, there is a real possibility that the corporation could never get started. Moreover, even if the corporation manages to stay in existence for some number of periods $t$, there is always the possibility that it will be bankrupted in period $t+1$ if the generation $t+1$ consumer refuses - for whatever reason - to buy the corporation's shares.

Note, however, that this same dilemma undermines the viability of fiat money. An agent might anticipate that a wealth windfall could be obtained by refusing to accept the fiat money currently in use, and by instead issuing a new form of fiat money. It was this fragility of fiat money that motivated the discussion by Samuelson (1958) regarding the significance of social compacts. By agreeing to accept fiat money issued by government as 'legal tender' in exchange for goods, 
private agents make it possible for this fiat money to act as a store of value and hence also as a medium of exchange. As noted by Bryant (1981), a violation of this social compact could lead to the demise of fiat money in any form.

This leads to a simple but important point: An organization will be able to incur and roll over a debt from one period to the next if and only if it obtains and maintains the confidence of savers. In the model presented here, the confidence that savers have in fiat money allows the government to incur and roll over a debt, while the confidence that savers have in share values allows a corporation to incur and roll over a debt. If confidence is lost in either financial asset for whatever reason, then the ability to roll over a debt is lost.

In reality, a variety of laws and regulations have been created to help citizens maintain confidence in debt instruments. Chartering and other types of regulations restrict the issuance of unsecured debt, just as various regulations protect government's monopoly over the issue of fiat money. As noted by Kaufman (1992, p. 296), among the requirements typically included for obtaining a commercial bank charter is a demonstration that the services proposed by the applicant are needed and will not endanger the solvency of other similar financial institutions.

In this paper we abstract from the issues of entry and confidence. Of course, the negative net worth position of our corporate intermediary might indeed make the default risk associated with our corporation's stock higher than that associated with a fiat money issued and protected by a government. Nevertheless, we are primarily concerned with the efficiency implications of government intermediation through fiat money versus private intermediation through a corporation. For comparison purposes, it seems reasonable to begin - as we do here - by examining the case where confidence is maintained in both assets and where both assets are protected from threat of entry. This allows us to explore whether or not a private earnings-driven intermediary can in principle enhance the efficiency of a monetarized economy. Once this basic understanding is obtained, we can proceed to extend our model by recognizing differences in risk and by exploring the extent to which social welfare might be improved through the regulation of private intermediaries.

\section{Equilibrium in the corporate economy}

As discussed in Section 3, the assumption that the corporation has structurally rational share demand expectations implies the nonviability of any prospectus with a zero share price $v_{t}$ and a positive subsequent share price $v_{t+1}$ or a positive share price $v_{t}$ and a zero subsequent share price $v_{t+1}$. Also, as will be clarified in Section 6 (Propositions 6.5 and 6.8), the optimizing corporation will select the null prospectus with uniformly zero share prices if and only if 
the initial real money supply happens to equal the particular level needed to achieve a Pareto efficient outcome in the absence of the corporation.

Consequently, for expositional simplicity, the following definition of a Corporate Economy equilibrium focuses on those cases in which the optimizing private corporation plays a nontrivial role in the economy through strictly positive share price announcements.

Definition 5.1. Given an initial level of money balances $M_{0}>0$ and an initial level of share holdings $\theta_{0}>0$, a vector

$$
\boldsymbol{e}\left(M_{0}, \theta_{0}\right)=\left(\boldsymbol{c}, \boldsymbol{M}, \boldsymbol{\theta}, \boldsymbol{\theta}^{\mathrm{e}}, \boldsymbol{I}, \boldsymbol{P}\right)
$$

consisting of a consumption allocation $c=\left(c_{1}^{\mathrm{o}},\left(c_{1}^{\mathrm{y}}, c_{2}^{\mathrm{o}}\right),\left(c_{1}^{\mathrm{y}}, c_{2}^{\mathrm{o}}\right), \ldots\right)$, a nominal money demand sequence $\boldsymbol{M}=\left(M_{1}, M_{2}, \ldots\right)$, a share demand sequence $\boldsymbol{\theta}=\left(\theta_{1}, \theta_{2}, \ldots\right)$, a corporate expected share demand sequence $\boldsymbol{\theta}^{\mathrm{e}}=\left(\theta_{1}^{\mathrm{e}}, \theta_{2}^{\mathrm{e}}, \ldots\right)$, a corporate prospectus $\boldsymbol{I}=\left(\boldsymbol{v}, \boldsymbol{d}^{\mathrm{e}}\right)$ with $\boldsymbol{v}>0$, and a nominal goods price sequence $\boldsymbol{P}=\left(P_{1}, P_{2}, \ldots\right)$ is an equilibrium for the Corporate Economy, conditional on $M_{0}$ and $\theta_{0}$, if it satisfies the following five conditions:

- Positive nominal goods prices: $0<P_{t}$ for each $t \geq 1$.

- Consumer optimization: Consumer demands for goods, money, and shares constitute finite-valued solutions to the generation 0 consumer's budget constraint (8) and the lifetime utility maximization problem (2) for each $t \geq 1$.

- Corporate optimization: The prospectus $\boldsymbol{I}$ is an element of the corporation's optimal choice set $\mathscr{I}(\boldsymbol{P})$.

- Market clearing for goods and money: For each $t \geq 1$,

$$
\begin{aligned}
& w^{\mathrm{y}}+w^{\mathrm{o}} \geq c_{t}^{\mathrm{y}}+c_{t}^{\mathrm{o}}, \\
& M_{t-1} \geq M_{t} .
\end{aligned}
$$

- Fulfilled share and dividend expectations: For each $t \geq 1, \theta_{t}^{\mathrm{e}}=\theta_{t}$ and $d_{t}^{\mathrm{e}}=v_{t}\left[\theta_{t}-\theta_{t-1}\right] / \theta_{t-1}$.

The first condition excludes equilibria with zero nominal goods prices, although it does permit the price of money, $1 / P_{t}$, to be zero in finite time. In the latter case, only shares can be used to store value. The consumer optimization condition ensures that each consumer is maximizing his utility, conditional on expected prices and dividends, and the corporate optimization condition ensures that the corporation is acting in accordance with the interests of its shareholders.

The goods market clearing condition (15) ensures the feasibility of the equilibrium consumption allocation. The money market clearing condition (16) ensures that the demand for money in period $t$ does not exceed the supply, which is given by the amount of money held by the generation $t-1$ old agent. Recall that 
government only issues money in period 1 . The absence of a market clearing condition for shares implies that the corporation can freely issue new shares in each period $t$. Consequently, the number of shares $\theta_{t-1}$ which the generation $t-1$ old consumer redeems in period $t$ places no direct restriction on the number of shares $\theta_{t}$ that can be issued to the generation $t$ young consumer.

The final condition ensures that the corporation's share demand and dividend expectations are correct.

\section{Efficiency and dynamic properties}

If the corporation is eliminated from the Corporate Economy, i.e., if share prices and expected dividend distributions are simply constrained to be zero, then the Corporate Economy reduces to the basic monetary OG economy. The no-trade outcome in which money is without value and each consumer in each period $t$ simply consumes his own endowment can be supported as a competitive equilibrium for the latter economy; and, given the regularity condition (1), this no-trade outcome is not Pareto efficient (Gale, 1973). How is the economy affected by the introduction of a private, earnings-driven, price-setting corporation that issues and rolls over debt?

To begin the analysis of this question, consider the summation of the youngage budget constraint of the generation $t$ consumer and the old-age budget constraint of the generation $t-1$ consumer. Assuming that dividend expectations are fulfilled, one obtains

$$
0=\left[w^{\mathrm{y}}+w^{\mathrm{o}}-c_{t}^{\mathrm{y}}-c_{t}^{\mathrm{o}}\right]+\left[M_{t-1}-M_{t}\right] / P_{t}, \quad t \geq 1 .
$$

The market clearing conditions (15) and (16) for goods and money then imply that

$$
\begin{aligned}
& 0=w^{\mathrm{y}}+w^{\mathrm{o}}-c_{t}^{\mathrm{y}}-c_{t}^{\mathrm{o}}, \quad t \geq 1, \\
& 0=\left[M_{t-1}-M_{t}\right] / P_{t}, \quad t \geq 1 .
\end{aligned}
$$

Recalling that the generation $t$ savings level is defined by $s_{t} \equiv w^{y}-c_{t}^{\mathrm{y}}$ for each $t \geq 1$, it follows from the budget constraint (6) and the goods market clearing condition (18) that

$$
s_{t+1}=q_{t} s_{t}, \quad t \geq 1 .
$$

Moreover, since share prices are positive in any Corporate Economy equilibrium, the first-order condition (3) applies and can be expressed as

$$
\operatorname{MRS}\left(w^{\mathrm{y}}-s_{t}, w^{\mathrm{o}}+q_{t} s_{t}\right)=q_{t}, \quad t \geq 1 .
$$


Given a value for the initial share rate of return $q_{1}$, relations (20) and (21) determine all possible equilibrium paths for $s_{t}$ and $q_{t}$.

In the following subsections the efficiency and dynamic properties of corporate economy equilibria are examined, first under the assumption that consumer preferences exhibit gross substitutability, and then without this assumption. The next two propositions will be useful for this purpose. The first proposition establishes a uniform positive lower bound on the share rates of return in any Corporate Economy equilibrium.

Proposition 6.1. In any Corporate Economy equilibrium, the share rates of return $q_{t}$ satisfy $q_{t} \geq \operatorname{MRS}\left(w^{\mathrm{y}}, w^{\mathrm{o}}\right)$ for all $t \geq 1$.

Recalling Proposition 2.1, it follows from Proposition 6.1 that all young consumers in a Corporate Economy equilibrium choose nonnegative savings levels $s_{t}$. The next proposition relies on the well-known Cass-Balasko-Shell 'transversality condition' elaborated in Balasko and Shell (1980, Proposition 5.6, p. 296) to obtain a general characterization of Pareto inefficient consumption allocations for the corporate economy in terms of the long-run behavior of these savings levels.

Proposition 6.2. Let $\boldsymbol{e}\left(M_{0}, \theta_{0}\right)=\left(\boldsymbol{c}, \boldsymbol{M}, \theta, \theta^{\mathrm{e}}, \boldsymbol{I}, \boldsymbol{P}\right)$ denote an equilibrium for the Corporate Economy. Suppose the equilibrium consumption profiles $\left(c_{t}^{\mathrm{y}}, c_{t+1}^{\mathrm{o}}\right)$ are uniformly bounded above and below by strictly positive vectors. Then $\boldsymbol{c}$ is a Pareto inefficient consumption allocation if and only if $\lim _{t \rightarrow \infty} s_{t}=0$, where $s_{t} \equiv\left[w^{y}-c_{t}^{y}\right]$.

\subsection{Efficiency and dynamic properties under gross substitutability}

As established in Proposition 2.1, the optimal savings level of each consumer is uniquely determined as a function $s(q)$ of the share rate of return $q$ for each $q>0$. Suppose the preferences of consumers in the Corporate Economy satisfy gross substitutability, in the sense that $s(q)$ is a strictly increasing function of $q$. In this case, each optimal savings level is supported by a unique rate of return, and at most one equilibrium path for $q_{t}$ and $s_{t}$ is associated with each initial rate of return $q_{1}$. As shown in Fig. 1, the offer curve for the generation $t$ consumer is everywhere negatively sloped.

In any stationary-structured OG economy such as the Corporate Economy, the 'golden rule' rate of return is defined to be the stationary rate of return $\bar{q}$ that supports the highest possible lifetime utility for a representative consumer. As shown by Samuelson (1958), this rate of return (in gross terms) coincides with 1 plus the population growth rate $g$, where $g$ is assumed to be zero for the Corporate Economy. The golden rule consumption profile and savings level supported by the Corporate Economy golden rule rate of return $\bar{q}=1$ are 


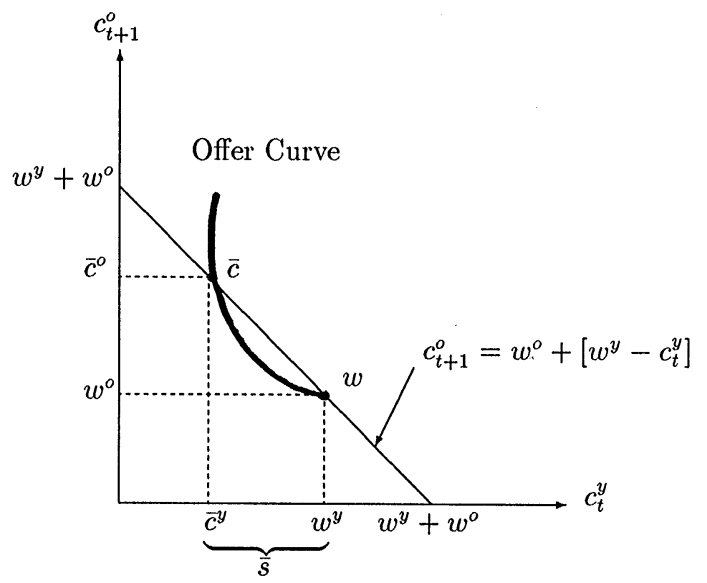

Fig. 1.

depicted in Fig. 1 as $\bar{c}=\left(\bar{c}^{\mathrm{y}}, \bar{c}^{\mathrm{o}}\right)$ and $\bar{s} \equiv w^{\mathrm{y}}-\bar{c}^{\mathrm{y}}$, respectively. Given the regularity conditions imposed on preferences in Section $2, \bar{q}=1$ is strictly greater than $M R S\left(w^{\mathrm{y}}, w^{\mathrm{o}}\right)$, and $\bar{c}^{\mathrm{y}}, \bar{c}^{\mathrm{o}}$, and $\bar{s}$ are necessarily positive. Consequently, it follows from Proposition 6.2 that any Corporate Economy equilibrium supported by the stationary golden rule rate of return $\bar{q}=1$ is Pareto efficient.

Do any such equilibria exist? The next proposition provides a first step toward answering this question.

Proposition 6.3. Given gross substitutability, in any Corporate Economy equilibrium the optimizing corporation must set $q_{1}=1$.

As seen in the appendix proof of this proposition, $q_{1}>1$ violates the assumption that the corporation chooses a corporate plan it perceives to be viable, and $q_{1}<1$ violates the assumption that the corporation acts in the best interests of its shareholders. This raises two new questions. Do any Corporate Economy equilibria exist that support the initial share rate of return $q_{1}=1$ ? If so, what are their efficiency properties? The following proposition answers both of these questions.

Proposition 6.4. Given gross substitutability, the only possible Corporate Economy equilibria are the Pareto efficient golden rule equilibria supported by $q_{t}=1$ for all $t \geq 1$, and the set of such equilibria is not empty.

Proposition 6.4 shows that the corporation has a dramatic impact on the efficiency and dynamic properties of the Corporate Economy. Assuming gross substitutability, the economy has a unique equilibrium consumption allocation, 
namely, the Pareto efficient golden rule consumption allocation characterized by the stationary consumption profile $\bar{c}$, as depicted in Fig. 1 . As noted in the appendix proof of Proposition 6.4, this unique equilibrium consumption allocation can be supported by Corporate Economy equilibria entailing different corporate plans $\boldsymbol{I}$, money demand sequences $\boldsymbol{M}$, share demand sequences $\boldsymbol{\theta}$, expected share demand sequences $\boldsymbol{\theta}^{\mathrm{e}}$, and price sequences $\boldsymbol{P}$.

In contrast, Gale (1973) establishes that the basic monetary OG economy with preferences satisfying gross substitutability and the regularity condition (1) has infinitely many equilibrium consumption allocations. Only one of these consumption allocations - the golden rule consumption allocation supported by the stationary rate of return $\bar{q}=1-$ is Pareto efficient. All other equilibrium consumption allocations are Pareto inefficient and are associated with initial rates of return that are less than one. In the Corporate Economy an initial rate of return less than one on both money and shares gives the corporation an opportunity to increase the welfare of each of its shareholders by raising the initial rate of return on shares and by increasing its issue of unsecured debt. Since active private financial intermediaries are missing in the basic monetary OG economy, however, this opportunity is not exploited.

Proposition 6.4 also highlights the fundamental trade-off between efficiency and stability in both the Corporate Economy and the basic monetary OG economy. Assuming gross substitutability, the setting of an initial rate of return exceeding one ultimately results in insolvency for either economy. For example, making repeated use of relation (20) and gross substitutability, a simple induction argument establishes that the optimal savings sequence $\left(s_{t}\right)$ for the Corporate Economy must diverge if $q_{1}>1$, implying that the finite resources $w^{y}+w^{o}$ available in the economy in each period $t$ are exceeded in finite time. The drive of an active earnings-driven corporation to enhance the welfare of its shareholders pushes the initial rate of return to $q_{1}=1$. This increases efficiency, but it also pushes the economy to the brink of collapse. Similarly, for the basic monetary OG economy, a government monetary policy designed to achieve efficiency would (if possible) set the initial rate of return on money to one and hence also push the economy to the brink of collapse.

Although the set of possible Corporate Economy equilibria exhibits a considerable degree of indeterminacy with regard to the setting of nominal variables, some interesting inferences can be drawn from the finding in Proposition 6.4 that the equilibrium wealth windfall of the generation 0 old consumer, $M_{0} / P_{1}+\left[v_{1}+d_{1}\right] \theta_{0}$, must equal the golden rule savings level, $\bar{s}$. Since $\left[v_{1}+d_{1}\right] \theta_{0} \geq 0$, this relation implies that the initial real money supply, $M_{0} / P_{1}$, cannot exceed $\bar{s}$ in equilibrium. As the next proposition shows, the corporation has a viable way to enter the economy if and only if $M_{0} / P_{1}<\bar{s}$.

Proposition 6.5. Let $M_{0}>0$ and $\theta_{0}>0$ be given, and suppose consumer preferences satisfy gross substitutability. Then in order for a Corporate Economy 
equilibrium $\boldsymbol{e}\left(M_{0}, \theta_{0}\right)$ to exist, the nominal goods prices $\left(P_{1}, P_{2}, \ldots\right)$ must satisfy $M_{0} / P_{1}<\bar{s}$ and $P_{t}=P_{t+1}$ for $t \geq 1$. Conversely, given any such prices, there exists a Corporate Economy equilibrium $\boldsymbol{e}\left(M_{0}, \theta_{0}\right)$ that generates these prices, and the market value of the corporation in this equilibrium is given by $v_{t} \theta_{t}=\left[\bar{s}-M_{0} / P_{1}\right]>0$ in each period $t \geq 1$.

Consequently, if preferences exhibit gross substitutability, then government can prevent the viable entry of a private corporation issuing unsecured debt if it can set the initial real money supply equal to the golden rule level $M_{0} / P_{1}=\bar{s}$. In this special case, the Pareto efficient golden rule outcome is achieved without the need of a private intermediary. On the other hand, if the initial real money supply is below this golden rule level for any reason, then a profit opportunity exists in the economy that can be exploited by the entry of a private intermediary willing to issue and forever roll over positively priced unsecured debt.

\subsection{Efficiency and dynamic properties without gross substitutability}

Suppose, instead, that consumer preferences fail to satisfy gross substitutability. The optimal consumption and savings levels of each consumer are still uniquely determined as functions $\left(c^{\mathrm{y}}(q), c^{\mathrm{o}}(q), s(q)\right)$ of the rate of return $q$ for each $q>0$. However, the absence of gross substitutability implies that there exist savings levels $s_{t}$ for which the first-order condition (21) determines at least two possible supporting rates of return $q_{t}$. Consequently, the mapping from $q$ to $s(q)$ is not one-to-one and the offer curve of each consumer bends back upon itself at least once, as illustrated in Fig. 2. It follows that more than one equilibrium path can be associated with an initial rate of return $q_{1}$.

In view of the potential complications caused by this indeterminacy of equilibrium paths, most researchers using the OG framework have assumed gross substitutability. An important exception is Grandmont (1985), who relies on the absence of gross substitutability to obtain an endogenous competitive business cycle. Here we establish various efficiency properties for the Corporate Economy in the absence of gross substitutability.

By assumption (1), the offer curve of each consumer has a slope $-\operatorname{MRS}\left(w^{\mathrm{y}}, w^{\mathrm{o}}\right)>-1$ at the endowment point $\left(w^{\mathrm{y}}, w^{\mathrm{o}}\right)$, implying that the optimal savings level $s(q)$ is a positive and increasing function of $q$ for sufficiently small $q>M R S\left(w^{\mathrm{y}}, w^{\mathrm{o}}\right)$. Suppose that the offer curve of each consumer is as depicted in Fig. 2. More precisely, suppose that the offer curve bends back upon itself only once, that the bend point is supported by a rate of return $q^{*}$ that is strictly less than one and strictly greater than $\operatorname{MRS}\left(w^{\mathrm{y}}, w^{\mathrm{o}}\right)$, and that the optimal old-age consumption level $c^{0}(q)$ implied by this offer curve is a strictly increasing function of $q$ for all $q \geq \operatorname{MRS}\left(w^{\mathrm{y}}, w^{\mathrm{o}}\right)$ and satisfies $\lim _{q \rightarrow+\infty} c^{\mathrm{o}}(q)=+\infty$. Given these restrictions on the offer curve of each consumer, the Corporate 


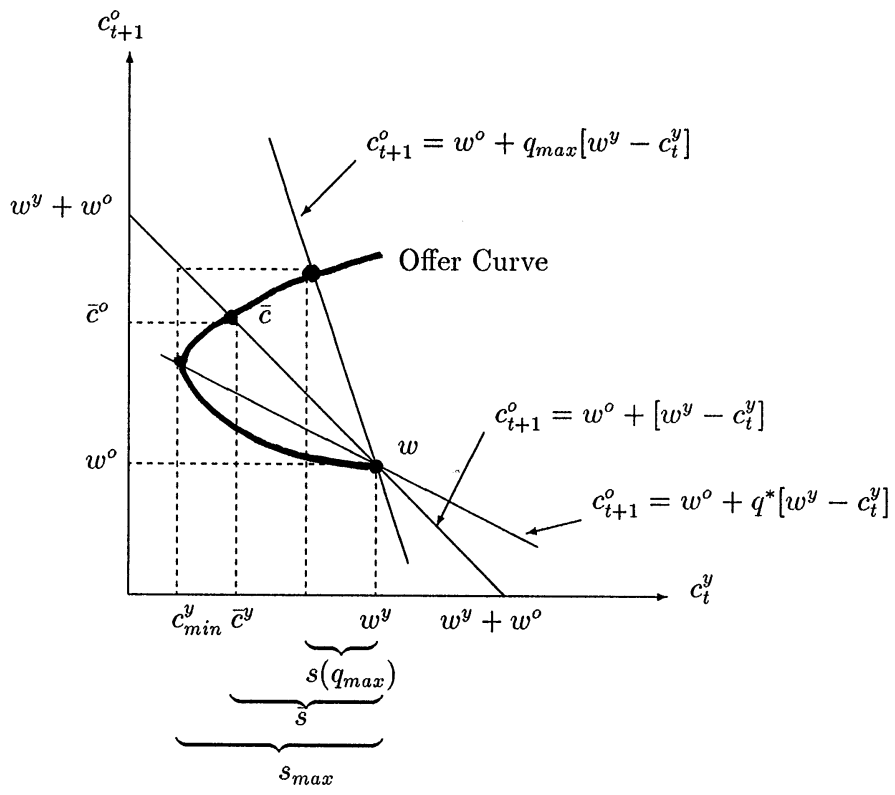

Fig. 2.

Economy in the absence of the corporation essentially reduces to the basic monetary OG economy studied by Grandmont (1985).

To understand more clearly what is depicted in Fig. 2, suppose $\boldsymbol{q}=\left(q_{1}, q_{2}, \ldots\right)$ is an equilibrium sequence of return rates. Let $A$ be a point on the offer curve in Fig. 2 that is associated with the equilibrium savings level $s\left(q_{t}\right)=w^{y}-c^{y}\left(q_{t}\right)$ for the young consumer in period $t$. Note that the projection of $A$ onto the vertical axis gives the equilibrium consumption level $c^{\mathrm{o}}\left(q_{t}\right)=w^{\mathrm{o}}+q_{t} s\left(q_{t}\right)$ for the old consumer in period $t+1$. Now move horizontally from $A$ to a corresponding point $B$ on the line $c_{t+1}^{\mathrm{o}}=w^{\mathrm{o}}+\left[w^{\mathrm{y}}-c_{t}^{\mathrm{o}}\right]$. The old-age consumption level at $B$ is the same as at $A$. However, because point $B$ is on a line with a slope equal to -1 , it follows from the goods market clearing condition (18) that the projection of $B$ onto the horizontal axis must yield the equilibrium consumption level $c^{\mathrm{y}}\left(q_{t+1}\right)=w^{\mathrm{y}}+w^{\mathrm{o}}-c^{\mathrm{o}}\left(q_{t}\right)$ for the young consumer in period $t+1$. The equilibrium savings level $s\left(q_{t+1}\right)$ for the young consumer in period $t+1$ is then given by the distance $w^{\mathrm{y}}-c^{\mathrm{y}}\left(q_{t+1}\right)$, which by construction equals $c^{\mathrm{o}}\left(q_{t}\right)-w^{\mathrm{o}}=q_{t} s\left(q_{t}\right)$. This is simply a geometric illustration of condition (20), shown earlier to be a necessary condition for equilibrium.

Let $s_{\max }$ denote the maximum possible level for the consumer's optimal savings, achieved at the first and only bend point in the offer curve. By assumption, this maximum savings level is supported by the rate of return $q^{*}$, 
i.e., $s_{\max }=s\left(q^{*}\right)$. Note that $s_{\max }$ in Fig. 2 is associated with a rate of return $q_{\max }$ through the relation $s_{\max }=q_{\max } s\left(q_{\max }\right)$. Recalling (20), this relation has the following interpretation: Given the rate of return $q_{\max }$ in some period $t$, the equilibrium savings level for period $t+1$ is $s_{\max }$. For later purposes, various properties of $s_{\max }$ and $q_{\max }$ depicted in Fig. 2 will now be established analytically.

Proposition 6.6. Suppose the offer curve of the consumer bends back upon itself exactly once, at a point supported by a rate of return $q^{*}$ satisfying $\operatorname{MRS}\left(w^{\mathrm{y}}, w^{\mathrm{o}}\right)<q^{*}<1$, and that the optimal old-age consumption level $c^{\mathrm{o}}(q)$ is a strictly increasing function of $q$ for all $q \geq M R S\left(w^{y}, w^{o}\right)$ and satisfies $\lim _{q \rightarrow+\infty} c^{\mathrm{o}}(q)=+\infty$. Then $\bar{s}<s_{\max }<w^{\mathrm{y}}$, and there exists a unique solution $q_{\max }$ to the equation $s_{\max }=q s(q)$, where $q_{\max }>1$. Moreover, in any Corporate Economy equilibrium the share rates of return $q_{t}$ lie in the interval $\left[M R S\left(w^{\mathrm{y}}, w^{\mathrm{o}}\right), q_{\max }\right]$, and the consumption profiles $\left(c_{t}^{\mathrm{y}}, c_{t+1}^{\mathrm{o}}\right)$ are uniformly bounded above and below by strictly positive vectors.

Proposition 6.6 can now be used to establish a first welfare theorem for the Corporate Economy in the absence of gross substitutability. In particular, given the assumptions of Proposition 6.6, if any Corporate Economy equilibrium failed to be Pareto efficient, then the equilibrium savings levels $s_{t}$ would have to converge to zero. As detailed in the appendix proof of the next result, however, the corporation could then select and implement a viable alternative prospectus that increases the utility of every consumer - specifically, that increases the windfall return of the generation 0 old consumer and increases the share rate of return $q_{t}$ for all consumers in subsequent generations $t$ - thus contradicting the maintained assumption that the economy was originally in a Corporate Economy equilibrium.

Proposition 6.7. Under the assumptions of Proposition 6.6, all Corporate Economy equilibria are Pareto efficient.

Several important questions still need to be addressed. Do equilibria necessarily exist for the Corporate Economy in the absence of gross substitutability? If so, what dynamic properties do they exhibit?

The next proposition establishes that equilibria do exist, given the assumptions of Proposition 6.6 and an additional restriction on the curvature of the upper branch of the offer curve. Moreover, the equilibrium paths of all real variables are uniquely determined. Interestingly, in the absence of the additional curvature restriction, the optimizing corporation may exhibit time-inconsistent behavior - i.e., a desire in some period $t>1$ to veer away from the prospectus announced in period 1 in order to improve the welfare of its shareholders. We shall return to this point at the end of this section. 
Proposition 6.8. Suppose the assumptions of Proposition 6.6 hold. In addition, suppose the degree to which the offer curve bends back upon itself is sufficiently modest, in the sense that

$$
q_{\max } \geq 1 / q^{*} .
$$

Then there exist infinitely many Corporate Economy equilibria, but all of these equilibria entail the same real equilibrium solution values for consumption levels, savings levels, and share rates of return. In particular, in any Corporate Economy equilibrium, the optimizing corporation sets $q_{1}=q^{*}$, and all equilibrium share rates of return $q_{t}$ lie in the interval $\left[q^{*}, q_{\max }\right]$, implying that the economy is always on the upper branch of the offer curve.

As detailed in the appendix proof of Proposition 6.8, the unique equilibrium share rates of return and savings levels for the Corporate Economy are given by the solution values $q_{t}^{*}$ and $s_{t}^{*}$ for the differential system (20) and (21), starting from the particular initial share rate of return $q_{1}^{*}=q^{*}$, and using the 'selection principle' implied by the optimizing behavior of the corporation that the highest possible share rate of return is always to be selected when multiple solutions are possible. On the other hand, equilibrium nominal prices are nonunique. Specifically, any nominal price sequence generated by $P_{t}^{*}=\left[q_{t-1}^{*} \cdots q_{1}^{*}\right]^{-1} P_{1}^{*}$ for each $t \geq 2$, with $P_{1}^{*}$ satisfying $0 \leq M_{0} / P_{1}^{*}<s_{\max }$, constitutes an equilibrium nominal price sequence.

An informal summary of the appendix proof for Proposition 6.8, will now be sketched. Although heuristic, it may help to clarify why the presence of the optimizing corporation ensures the determination of a unique real equilibrium outcome, despite the existence of a backward-bending offer curve.

Let $M_{0}$ and $\theta_{0}$ be any given positive values for the money and share holdings of the generation 0 consumer. In any Corporate Economy equilibrium the windfall return of the generation 0 consumer, $M_{0} / P_{1}+\left[v_{1}+d_{1}^{\mathrm{e}}\right] \theta_{0}$, must equal the savings level $s_{1}$ of the generation 1 consumer. Given the assumptions of Proposition 6.6, the maximum possible value for $s_{1}$ is $s_{\max }$.

Let $P_{1}^{*}$ denote any positive (possibly infinite) nominal price level for period 1 that satisfies $0 \leq M_{0} / P_{1}^{*}<s_{\max }$. Then, taking $M_{0} / P_{1}^{*}$ and $\theta_{0}$ as given, it follows from the definition of a Corporate Economy equilibrium that the optimizing corporation sets $\left[v_{1}+d_{1}^{\mathrm{e}}\right]$ in period 1 so that the windfall return of the generation 0 consumer is equal to $s_{\max }$. Given this promised windfall to the generation 0 consumer, the highest feasible rate of return that the corporation can offer to the generation 1 consumer is $q_{1}^{*} \equiv q^{*}$, resulting in the savings level $s_{1}^{*}=s\left(q^{*}\right) \equiv s_{\max }$; for setting any higher rate of return would result in a lower savings level, and the corporation would not be able to fulfill its contractual obligations to the generation 0 consumer.

By relation (20), the equilibrium savings level for period 2 must then be given by $s_{2}^{*}=q_{1}^{*} s\left(q_{1}^{*}\right)<s_{\max }$. The restriction (22) implies that $s_{2}^{*} \geq s\left(q_{\max }\right)$. 
Consequently, as depicted in Fig. 2, two possible rates of return $q_{2}$ support the savings level $s_{2}^{*}-$ i.e., two possible rates of return $q_{2}$ satisfy relation (21) for the given $s_{2}^{*}$ - and neither of these rates of return exceeds $q_{\max }$. It follows from the definition of a Corporate Economy equilibrium, however, that the optimizing corporation always chooses the highest possible rate of return for each successive generation. The economy thus moves along the upper branch of the offer curve, the branch that passes through the golden rule consumption point $\bar{c}$.

Continuing this line of reasoning, the equilibrium savings levels $s^{*}$ and rates of return $q_{t}^{*}$, and hence also the equilibrium consumption levels $c_{t}^{\mathrm{y}^{*}}$ and $c_{t+1}^{\mathrm{o}^{*}}$, are uniquely determined by successive applications of relations (20) and (21), together with the selection principle that the highest possible rate of return is always to be chosen. The regularity condition (22) guarantees that the rates of return $q_{t}^{*}$ all lie in the interval $\left[q^{*}, q_{\max }\right]$, hence the economy remains on the upper branch of the offer curve for all periods $t \geq 1$.

As noted in the appendix proof of Proposition 6.8, infinitely many Corporate Economy equilibria can be constructed to support this unique real equilibrium solution for consumption, savings, and share rates of return. One source of indeterminacy is the degree of freedom the corporation has to realize the rates of return $q_{t}^{*}$ either in the form of share price appreciation or in the form of dividend distributions. Another source of indeterminacy is the setting of the initial real money balance $M_{0} / P_{1}^{*}$. In analogy to the case of gross substitutability, the corporation is viable as long as this initial real money balance is strictly less than $s_{\max }$, the maximum possible level for consumer savings; for this permits the corporation to issue and roll over positively valued shares in each period $t \geq 1$.

What dynamic properties are exhibited by the unique real equilibrium solution for the Corporate Economy in the absence of gross substitutability? The next proposition establishes that only three relatively simple types of dynamic behavior are possible.

Proposition 6.9. Under the hypotheses of Proposition 6.8, only three types of dynamic behavior are possible for the rate of return sequence $\left(q_{t}^{*}\right)$ in any Corporate Economy equilibrium: either (a) condition (22) holds as an equality and the sequence $\left(q_{t}^{*}\right)$ cycles back and forth between $q^{*}$ and $q_{\max }$ in a period-2 orbit, starting with $q_{1}^{*}=q^{*}$; or (b) condition (22) holds as a strict inequality and the sequence $\left(q_{t}^{*}\right)$ converges to a limit cycle supported by a period-2 orbit $\left\{q_{\mathrm{L}}, q_{\mathrm{U}}\right\}$ with $q^{*}<$ $q_{\mathrm{L}}<1<q_{\mathrm{U}}<q_{\max }$ and $q_{\mathrm{L}} q_{U}=1$; or (c) condition (22) holds as a strict inequality and the sequence $\left(q^{*}\right)$ converges cyclically to the golden rule rate of return $\bar{q}=1$.

In summary, under the hypotheses of Proposition 6.8, an equilibrium path for the Corporate Economy either exhibits a deterministic and endogenously generated period 2 'business cycle' or converges cyclically to the golden rule consumption allocation. In either case, however, it follows from Proposition 6.7 that the equilibrium path is Pareto efficient. 
If condition (22) does not hold, implying that $q^{*} s\left(q^{*}\right)<s\left(q_{\max }\right)$, then the Corporate Economy may have no equilibria satisfying Definition 5.1. Roughly stated, the difficulty is that the corporation may wish to re-optimize its initial period 1 prospectus at some later time $t>1$ in order to improve the welfare of its subsequent shareholders, but Definition 5.1 does not permit re-optimization. Moreover, even if re-optimization were permitted, this would not fully resolve the resulting time-inconsistency problem.

To see the problem, recall that it is always in the best interest of the generation 0 shareholder if the corporation sets $q_{1}=q^{*}$ in period 1 to ensure that the generation 1 shareholder saves the maximum amount $s\left(q^{*}\right)=s_{\max }$. The consumer budget constraints and the product market clearing condition embodied in condition (20) then imply that the savings level $s_{2}$ of the generation 2 shareholder must equal $q^{*} s\left(q^{*}\right)$.

Two different rates of return $q_{2}^{\prime}$ and $q_{2}^{\prime \prime}$ support the savings level $s_{2}=q^{*} s\left(q^{*}\right)$ in period 2, with $q_{2}^{\prime}<q^{*}<1<q_{2}^{\prime \prime}$. If the regularity condition (22) fails to hold, however, the higher rate of return $q_{2}^{\prime \prime}$ exceeds $q_{\max }$ and is thus not feasible by Proposition 6.6. Suppose, then, that the corporation in period 1 announces a prospectus with a first period rate of return $q^{*}$ and a second period rate of return $q_{2}^{\prime}$.

The period 1 rate of return $q^{*}$ ensures that the generation 1 shareholder chooses the maximum possible savings level and hence that the generation 0 old shareholder receives the maximum possible windfall return. Once period 2 is actually reached, however, the rate of return $q_{2}^{\prime}$ is not in the best interest of either the generation 1 old shareholder or the generation 2 young shareholder. Rather, these shareholders would best be served if the corporation were now to increase $q_{2}^{\prime}$ to $q^{*}$. This change is feasible and would generate the maximum savings level from the generation 2 young shareholder and hence an unexpected windfall return for the generation 1 old shareholder. Unfortunately, if the generation 1 young shareholder perceives a positive probability that he will receive a windfall return from the corporation in period 2 -i.e., a return above and beyond the return generated by the dividend and/or share price appreciation promised in the initial prospectus - then he might lower his savings level in period 1 below $s_{\max }$, making the generation 0 old shareholder worse off.

In short, to handle a modified definition of equilibrium under which reoptimization is permitted, more detail would have to be added to the model concerning how the consumers behave in the uncertain environment created by the possibility of time-inconsistent corporate choice.

\section{Conclusion}

Trade and credit arrangements in modern market economies are primarily accomplished through earnings-driven private intermediaries such as retail 
stores, banks, and brokerage firms. Understanding how private intermediaries affect the allocation of resources is therefore of considerable importance. The findings of this paper suggest that the inclusion of private intermediaries is essential for the study of efficiency in OG economies, even in the absence of transactions costs and asymmetric information problems. In particular, it is shown that a first welfare theorem can be recovered for the basic monetary OG economy if the economy is generalized to encompass a corporate intermediary that maximizes its market value in direct accordance with the interests of its successive shareholders.

Further work is, of course, needed to check the robustness of these findings. One important issue is the degree of market power exercised by private intermediaries. In this paper it is assumed that the corporate intermediary announces share prices and dividend payments to its prospective shareholders and hence attempts to control the rate of return on the holding of its shares. Because of product differentiation, chartering restrictions, and so forth, actual financial intermediaries often do exercise some market power in setting rates of return for local deposits and loans (Hannan and Berger, 1991), but the intermediary may be too small relative to the securities market to influence its marginal funding costs and its marginal earnings on other financial assets such as large-denomination certificates of deposit (Fama, 1985).

The issue of market power is closely tied to the issue of entry. Empirical findings suggest that chartering and other restrictions currently in force do reduce initial entry into financial markets (Amel and Liang, 1992), but the special features of financial intermediaries that might warrant such particular forms of supervision are still under debate. Nearly all arguments for the regulation of private financial intermediaries to date have been based on the belief that information problems are particularly severe in financial markets (Gertler, 1988; Williamson, 1992; Bhattacharya and Thakor, 1993). This paper suggests that some form of initial entry deterrence may be necessary to ensure the long-run viability of private financial intermediaries, even in the absence of information problems; but complete deterrence resulting in a sole reliance on financial assets passively supplied by government to coordinate trade and credit will generally be inefficient.

Another interesting area for future research concerns the relationship between efficiency and private intermediation in $\mathrm{OG}$ economies with capital accumulation. Pingle and Tesfatsion (1997) show that the inclusion of a private earningsdriven corporate intermediary can eliminate the inefficiency that arises in the one-sector OG growth model studied by Diamond (1965) and Tirole (1985). Still unresolved, however, is whether private intermediation alleviates the 'inadequate distribution of capital among firms' described by Malinvaud $(1953,1962)$ that can arise in multi-sector growth models when the production decisions of individual firms result in aggregate capital overaccumulation. More generally, it would be of great interest to study the efficiency implications of private financial 
intermediation in OG growth models when agents of the same generation have heterogeneous endowments, tastes, and/or beliefs as well as heterogeneous production opportunities. One possible means for doing this would be to adopt an agent-based computational economics approach, a specialization to economics of the basic artificial life paradigm; see Tesfatsion (1997).

Finally, Grandmont (1985) stresses the importance of taking due account of learning when formulating the dynamics of an economy. In particular, he establishes for the basic monetary OG economy that the stability properties of equilibria depend on the processes that agents use to form their price expectations, and this point is surely relevant for the Corporate Economy as well. Interestingly, as seen in Section 6, another type of learning problem also arises for the Corporate Economy: namely, in the absence of gross substitutability, it can happen that the corporate intermediary will face a time inconsistency problem. That is, in some period $t>1$ the corporate intermediary might desire to deviate from the corporate plan it announced in period 1 in order to increase the welfare of its current and future shareholders. In this case the dynamic path of the economy cannot be determined without a more fully articulated modeling of consumer decision making in the face of uncertain corporate behavior.

\section{Appendix A. Outline of proposition proofs}

Proof of Proposition 2.1. By assumption, consumers take as given the positive, possibly infinite-valued prices for goods. If the price $P_{t}$ for good $t$ is finite, it follows from the budget constraints for problem (2) that the gross rate of return on holding money from period $t$ to $t+1, r_{t} \equiv\left[P_{t} / P_{t+1}\right] \geq 0$, must satisfy $r_{t} \leq q_{t}$ in order for problem (2) to have a finite solution. Given $r_{t} \leq q_{t}$, the budget constraints for problem (2) reduce to (5) and (6), and the optimal consumption and savings levels of the generation $t$ consumer are uniquely determined as functions of $q_{t}$ by relations (3), (5) and (6). Moreover, the regularity condition (1) implies that $s\left(q_{t}\right) \geq 0$ if and only if $q_{t} \geq M R S\left(w^{y}, w^{0}\right)$.

Suppose, instead, that $P_{t}$ and $P_{t+1}$ are both infinite. Then the real money balances of the generation $t$ consumer are zero-valued regardless of his choice of nominal money holdings $M_{t}$. Consequently, the budget constraints for problem (2) once again reduce to (5) and (6), and the remaining assertions of Proposition 2.1 follow as for the case when $P_{t}$ is finite. Finally, if $P_{t}$ takes on an infinite value but $P_{t+1}$ is finite, then problem (2) has no solution since the generation $t$ consumer will desire to hold an arbitrarily large amount of (costless) money in period $t$. Q.E.D.

Proof of Proposition 6.1. By Proposition 2.1, $s(q) \geq 0$ if and only if $q \geq \operatorname{MRS}\left(w^{\mathrm{y}}, w^{\mathrm{o}}\right)$. Suppose there exists an equilibrium for the Corporate 
Economy in which $q_{t}$ first falls below $\operatorname{MRS}\left(w^{\mathrm{y}}, w^{\mathrm{o}}\right)$ in some period $t^{*} \geq 1$. The generation $t^{*}$ young consumer would then plan to borrow rather than to save, i.e., $c_{t^{*}}^{\mathrm{y}}>w^{\mathrm{y}}$. But the planned optimal savings of the generation $t^{*}-1$ old consumer are nonnegative, implying that $c_{t^{*}}^{0} \geq w^{\circ}$, since either this consumer is the initial old consumer or he faced a share rate of return $q_{t^{*}-1} \geq \operatorname{MRS}\left(w^{\mathrm{y}}, w^{\mathrm{o}}\right)$ in period $t^{*}-1$. The goods market clearing condition (18) thus fails for period $t^{*}$. It must therefore hold that $q_{t} \geq M R S\left(w^{y}, w^{o}\right)$ for all $t \geq 1$. Q.E.D.

Proof of Proposition 6.2. Let $p_{t} \equiv\left[q_{t-1} \cdots q_{1}\right]^{-1}>0$ denote the real price of good 1 measured in units of good $t, t \geq 2$, with $p_{1} \equiv 1$. Then $p_{t+1}=\left[1 / q_{t}\right] p_{t}$, where $q_{t}$ is uniformly bounded from below by the positive constant $\operatorname{MRS}\left(w^{\mathrm{y}}, w^{\mathrm{o}}\right)$ for all $t \geq 1$ by Proposition 6.1. It follows that Property $\mathrm{G}$ in Proposition 5.6 of Balasko and Shell (1980) holds. Also, recall from Section 2 that Properties C and $\mathrm{C}^{\prime}$ in this Balasko-Shell proposition are assumed to hold. Thus, applying the Balasko-Shell proposition to the Corporate Economy - a special case of the Balasko-Shell pure exchange OG economy in terms of its specifications for preferences, real endowments, and technology (nonstorable resource) - the equilibrium consumption allocation $c$ is Pareto inefficient if and only if $\sum_{t=1}^{t=+\infty} 1 / p_{t}$ is finite.

Since the optimal savings levels $s_{t}$ are bounded between 0 and $w^{\mathrm{y}}$ for $q_{t} \geq M R S\left(w^{y}, w^{o}\right)$, either $\lim \sup s_{t}=0$ or $\lim \sup s_{t}>0$. Suppose $\lim \sup s_{t}>0$. From condition (20), $s_{t+1}=\left[p_{t} / p_{t+1}\right] s_{t}$ for all $t \geq 1$, implying that $s_{t}=\left[p_{1} / p_{t}\right] s_{1}$ for all $t \geq 1$. If $s_{1}=0$, then $s_{t}=0$ for all $t \geq 1$, contradicting the supposition. Therefore, $s_{1}>0$. If $\lim _{t \rightarrow+\infty}\left[1 / p_{t}\right]=0$, then $\lim _{t \rightarrow+\infty} s_{t}=0$ again contradicting the supposition. Therefore, $\sum_{t=1}^{t=T}\left[1 / p_{t}\right]$ does not converge as $T \rightarrow+\infty$. Because $p_{t}>0$ for all $t \geq 1$, it follows that $\sum_{t=1}^{t=+\infty}\left[1 / p_{t}\right]=+\infty$.

Conversely, suppose $\lim \sup s_{t}=0$, which in turn implies that $\lim \sup c_{t}^{\mathrm{y}}=w^{\mathrm{y}}$ and $\lim \sup c_{t+1}^{o}=w^{\mathrm{o}}$. It follows from the regularity condition (1) that, for sufficiently small $\varepsilon$ in $(0,1)$, there exists a period $k$ such that $p^{t} / p^{t+1}=\operatorname{MRS}\left(c_{t}^{\mathrm{y}}, c_{t+1}^{\mathrm{o}}\right) \leq[1-\varepsilon]$ for all $t \geq k$. Defining

$$
\rho_{t} \equiv 1 / p_{t}=\left[\frac{1}{p_{2}} \frac{p_{2}}{p_{3}} \cdots \frac{p_{t-1}}{p_{t}}\right],
$$

one has $\rho_{t} \leq \rho_{k}[1-\varepsilon]^{t-k}$ for all $t \geq k$. Thus, $\sum_{t=k}^{t=+\infty} 1 / p_{t} \leq \rho_{k} / \varepsilon<+\infty$. Finally, since $\sum_{t=1}^{t=k} 1 / p_{t}<+\infty$, it follows that $\sum_{t=1}^{t=+\infty} 1 / p_{t}<+\infty$.

In summary, the equilibrium consumption allocation $c$ is Pareto inefficient if and only if $\lim \sup s_{t}=0$. However, $s_{t} \geq 0$ for all $t \geq 0$ implies that $\lim \sup s_{t}=0$ if and only if $\lim _{t \rightarrow \infty} s_{t}=0$. Q.E.D.

Proof of Proposition 6.3. Let a Corporate Economy equilibrium be given, characterized by a rate of return sequence $\left(q_{t}\right)$. By Propositions 2.1 and 6.1, $q_{t} \geq \operatorname{MRS}\left(w^{\mathrm{y}}, w^{\mathrm{o}}\right)$ and $s_{t} \geq 0$ for each $t \geq 1$. 
Suppose $q_{1} \geq k$ for some $k>1$. Then gross substitutability implies $s_{1}>\bar{s}$ and relation (20) implies $s_{2}>s_{1}$. Knowing $s_{2}>s_{1}$, gross substitutability implies $q_{2}>q_{1}$. Making repeated use of relation (20) and gross substitutability, a simple induction argument then establishes that $q_{t+1}>q_{t}$ for all $t \geq 1$, hence $q_{t} \geq k$ for all $t \geq 1$. It follows from the expression given by (13) for $q_{t}$ that $v_{t+1} \theta_{t+1}^{\mathrm{e}} \geq k v_{t} \theta_{t}^{\mathrm{e}}$ for all $t \geq 1$, which implies that the sequence of expected real share demands, $v_{t} \theta_{t}^{\text {e }}$, diverges to $+\infty$. But this violates the assumption in Section 3 that the optimizing corporation only chooses from among those prospectuses it perceives to be viable - implying, in particular, that the prospectus must entail a bounded sequence of expected real share demands. Consequently, in any Corporate Economy equilibrium, it cannot be true that $q_{1}>1$.

Suppose, instead, that $M R S\left(w^{\mathrm{y}}, w^{\mathrm{o}}\right) \leq q_{1}<1$. The corporation could then increase the welfare of each of its shareholders by making a viable change in its prospectus, a violation of the assumption that the corporation in any Corporate Economy equilibrium chooses a viable prospectus in accordance with the best interests of its shareholders. Specifically, as detailed in Pingle and Tesfatsion (1996, Appendix), the corporation could increase the welfare of the generation 0 consumer and each subsequent generation $t$ consumer, $t \geq 1$, by appropriately adjusting upwards the share rates of return $q_{t}, t \geq 1$. Q.E.D.

Proof of Proposition 6.4. Recall that $\bar{q}=1$ is the golden rule rate of return for the Corporate Economy. By Proposition 6.3, $q_{1}$ must equal 1 in any Corporate Economy equilibrium. Given $q_{1}=1$, it follows by gross substitutability that $s_{1}$ must equal the golden rule savings level $\bar{s}$. Also, relation (20) implies that $s_{2}=s_{1}$. Hence, applying gross substitutability once more, $q_{2}=q_{1}=1$. A simple induction argument then gives $q_{t}=1$ and $s_{t}=\bar{s}$ for all $t \geq 1$. Consequently, given gross substitutability, the only possible Corporate Economy equilibria are the Pareto efficient golden rule equilibria characterized in real terms by the stationary share rate of return $\bar{q}=1$, the stationary savings level $\bar{s}$ for each young consumer, and the stationary consumption levels $\bar{c}^{\mathrm{y}}$ and $\bar{c}^{\mathrm{o}}$ for each young and old consumer, respectively.

It can further be shown that there exists at least one golden rule equilibrium for the Corporate Economy. Specifically, suppose that the sequence $\boldsymbol{P}=\left(P_{1}, P_{2}, \ldots\right)$ of nominal goods prices is a positive sequence satisfying

$$
0 \leq M_{0} / P_{1}<\bar{s}, \quad P_{t}=P_{t+1}, t \geq 1 .
$$

Taking this sequence of nominal goods prices as given, suppose the corporation selects the prospectus $I^{*}$ defined as follows: the corporation sets $d_{t}^{\mathrm{e}}=0$ for all $t \geq 1$, sets $v_{1}>0$ so that $v_{1} \theta_{0}=\bar{s}-M_{0} / P_{1}$, and sets $v_{t}=v_{1}$ for all $t \geq 2$. Note that the share rates of return implied by this prospectus satisfy $q_{t}=1$ for all $t \geq 1$ by definition (4). Finally, suppose the share demands expected by the corporation under this prospectus are $\theta_{t}^{\mathrm{e}}=\theta_{0}$ for all $t \geq 1$. As detailed in Pingle and Tesfatsion (1996, Appendix), it is then straightforward if tedious to show 
that this prospectus is a viable prospectus that supports the golden rule allocation as the real outcome of a Corporate Economy equilibrium. Q.E.D.

Proof of Proposition 6.5. The necessity of having $M_{0} / P_{1} \leq \bar{s}$ in equilibrium follows from the fact that $M_{0} / P_{1}+\left[v_{1}+d_{1}\right] / \theta=\bar{s}$ in equilibrium, as established in Proposition 6.4. But, given $\theta_{0}>0, M_{0} / P_{1}=\bar{s}$ would force $\left[v_{1}+d_{1}^{\text {e }}\right]$ $=0$, a violation of the requirement that $v_{1}>0$ and $d_{1}^{\text {e }} \geq 0$. If $P_{1}<+\infty$, it follows from the money market clearing condition (19) that $M_{1}=M_{0}>0$, but the period 1 young consumer will only be willing to hold a positive amount of money in lieu of shares if $r_{1}=q_{1}=1$, implying $P_{1}=P_{2}$. A simple induction argument then yields the necessity of having $P_{t}=P_{t+1}$ for every $t \geq 1$ in any equilibrium. Conversely, if $P_{1}=+\infty$, no solution exists for the utility maximization problem (2) in period 1 unless $P_{2}=+\infty$; and a simple induction argument again yields the necessity of having $P_{t}=+\infty$ for all $t \geq 1$ in any equilibrium.

Given a nominal goods price sequence satisfying $M_{0} / P_{1}<\bar{s}$ and $P_{t}=P_{t+1}$ for each $t \geq 1$, together with gross substitutability, the proof of Proposition 6.4 establishes the existence of a Corporate Economy equilibrium with the market value of the firm given by $v_{t} \theta_{t}=\bar{s}-M_{0} / P_{1}>0$ for each $t \geq 1$. Q.E.D.

Proof of Proposition 6.6. The maximum optimal savings level $s_{\max }$ must be strictly less than $w^{\mathrm{y}}$; for otherwise a consumer would choose to consume nothing when young when faced with the rate of return $q^{*}$, an impossibility given the restrictions on $U(\cdot)$ imposed in Section 2. Moreover, the regularity condition (1), together with the assumption of a unique backward bend in the offer curve at $q^{*}<1$, implies that $s_{\max } \equiv s\left(q^{*}\right)$ is greater than the golden rule savings level $\bar{s}=s(1)$; see Fig. 2.

Since $q s(q)=c^{\mathrm{o}}(q)-w^{\mathrm{o}}$ is a strictly increasing function of $q$ that takes on the value 0 at $q=\operatorname{MRS}\left(w^{y}, w^{0}\right)$ and diverges to $+\infty$ as $q \rightarrow+\infty$, the equation $s_{\max }=q s(q)$ has a unique solution $q_{\max }>0$ for every $s_{\max }>0$. By definition of $s_{\max }$, the rate of return $q_{\max }$ must be greater than 1 ; for $q_{\max }<1$ would imply that $0<s_{\max }=q_{\max } s\left(q_{\max }\right)<s\left(q_{\max }\right) \leq s_{\max }$, a contradiction, and $q_{\max }=1$ would imply that $s_{\max }=\bar{s}$, another contradiction. Also, no share rate of return $q_{t}>q_{\max }$ can occur in any Corporate Economy equilibrium; for this would imply that the equilibrium savings rate $s_{t+1}=q_{t} s\left(q_{t}\right)$ for period $t+1$ exceeds $s_{\max }=q_{\max } s\left(q_{\max }\right)$, a contradiction of the definition of $s_{\max }$.

Since by assumption $c^{\circ}(q)$ is an increasing function of $q$, the finding $q_{t} \leq q_{\max }$, together with the goods market clearing condition (18) and Proposition 6.1, imply that $0<w^{\mathrm{o}}=c^{\mathrm{o}}\left(\operatorname{MRS}\left(w^{\mathrm{y}}, w^{\mathrm{o}}\right)\right) \leq c^{\mathrm{o}}\left(q_{t}\right) \leq c^{\mathrm{o}}\left(q_{\max }\right) \leq w^{\mathrm{o}}+w^{\mathrm{y}}, t \geq 1$, in any Corporate Economy equilibrium; i.e. the equilibrium old-age consumption levels are uniformly bounded above and below by positive-finite quantities. Finally, it follows from the goods market clearing condition (18) and the finding $s_{\max }<w^{\mathrm{y}}$ that $c^{\mathrm{y}}\left(q_{t}\right)$ must satisfy $0<w^{\mathrm{y}}-s_{\max } \leq w^{\mathrm{y}}-s\left(q_{t}\right)=c^{\mathrm{y}}\left(q_{t}\right) \leq w^{\mathrm{y}}+w^{\mathrm{o}}$, 
$t \geq 1$; i.e. the equilibrium young-age consumption levels are also uniformly bounded above and below by positive finite quantities. Q.E.D.

Proof of Proposition 6.7. Suppose there exists a Corporate Economy equilibrium for which the consumption allocation is not Pareto efficient. By Propositions 6.2 and 6.6 , the sequence $\left(s_{t}: t=1,2, \ldots\right)$ of (nonnegative) equilibrium savings levels $s_{t}$ must then converge to zero. In particular, given any $\varepsilon>0$, there exist at most finitely many periods $t$ such that $s_{t}>\varepsilon$.

Let $\varepsilon \equiv s\left(q_{\max }\right) / 2>0$. Then for each $b \leq \varepsilon$ the equation $s(q)=b$ has only one solution $q(b)$ satisfying $q(b) \leq q_{\max }$, and this solution satisfies $0<q(b) \leq q(\varepsilon)<q^{*}<1$; see Fig. 2. Let $k \geq 1$ be such that the equilibrium savings levels satisfy $s_{t}=s\left(q_{t}\right) \leq \varepsilon / 2$ for all $t \geq k$. By Proposition 6.6, the equilibrium rates of return are uniformly bounded above by $q_{\max }$ and below by $M R S\left(w^{y}, w^{0}\right)$. Hence, by choice of $\varepsilon$, the equilibrium rate of return $q_{t}$ for any period $t \geq k$ must satisfy $M R S\left(w^{\mathrm{y}}, w^{\mathrm{o}}\right) \leq q_{t}<q(\varepsilon)<q^{*}<1$. It follows from (20) that the (nonnegative) equilibrium savings rates $s_{t}$ converge to 0 and the equilibrium rates of return $q_{t}$ converge to $M R S\left(w^{\mathrm{y}}, w^{0}\right)$ as $t \rightarrow \infty$.

Suppose the corporation increases the rate of return from $q_{t}$ to $q(\varepsilon)<q^{*}$ in each period $t \geq k$ by setting new higher share prices $\left(\hat{v}_{t+1}: t \geq k\right)$ satisfying $\hat{v}_{t+1}=q(\varepsilon) \hat{v}_{t}$ for all $t \geq k$, with $\hat{v}_{k} \equiv v_{k}$, an appropriately increased expected dividend $\hat{d}_{k}^{\mathrm{e}}$ for period $k$, and zero expected dividends for all periods $t+1$ with $t \geq k$. As detailed in Pingle and Tesfatsion (1996, Appendix), these changes in its prospectus would be perceived by the corporation to be viable changes that would benefit each of its shareholders, contradicting the assumption that the economy was originally in a Corporate Economy equilibrium.

Consequently, it follows that any Corporate Economy equilibrium must support a Pareto efficient consumption allocation. Q.E.D.

Proof of Proposition 6.8. Consider the sequential generation of savings and rate of return sequences $\left(s_{t}^{*}\right)$ and $\left(q_{t}^{*}\right)$ by the relations (20) and (21), starting from the initial condition $q_{1}^{*}=q^{*}$, under the 'selection principle' that the highest rate of return is always to be chosen when multiple solutions are possible. It will first be shown (Lemma 2, below) that, under the regularity condition (22), such sequences can be generated because the rates of return $q_{t}^{*}$ all lie in the interval $\left[q^{*}, q_{\max }\right]$, implying in turn that the savings levels $s_{t}^{*}$ all lie in the feasibly supported interval $\left[s\left(q_{\max }\right), s\left(q^{*}\right)\right]$ with $s\left(q^{*}\right) \equiv s_{\max }$.

Lemma A.1. Condition (22) holds if and only if $q^{*} s\left(q^{*}\right) \geq s\left(q_{\max }\right)$.

Proof of Lemma A.1. By construction, $s_{\max } \equiv s\left(q^{*}\right)=q_{\max } s\left(q_{\max }\right)$, where $s\left(q^{*}\right)$ and $s\left(q_{\max }\right)$ are both strictly positive. Multiplying each side by $q^{*}$, the proof is immediate. Q.E.D. 
Lemma A.2. Suppose condition (22) holds as a strict inequality. Then, for all periods $m \geq 1$ and $k \geq 1$, one has: (a) if $q^{*} \leq q_{m}^{*}<q_{k}^{*}<1$, then $1<q_{k+1}^{*}<q_{m+1}^{*}$ $<q_{\max }$; and (b) if $1<q_{k}^{*}<q_{m}^{*}<q_{\max }$, then $q^{*}<q_{m+1}^{*}<q_{k+1}^{*}<1$.

Proof of Lemma A.2. By assumption, the optimal old-age consumption level $c^{\mathrm{o}}(q)=w^{\mathrm{o}}+q s(q)$ is a strictly increasing function of $q$ over the interval $q \geq q^{*}$, and the optimal savings level $s(q)$ is a strictly decreasing function of $q$ over $q \geq q^{*}$. Moreover, by (20), $s\left(q_{t+1}^{*}\right)=q_{t}^{*} s\left(q_{t}^{*}\right)$ for all $t \geq 1$. Hence, the conditional statement in (a) implies that $c^{\mathrm{o}}\left(q^{*}\right) \leq c^{\mathrm{o}}\left(q_{m}^{*}\right)<c^{\mathrm{o}}\left(q_{k}^{*}\right)<c^{\mathrm{o}}(1)$, which in turn implies, using (20) and (22), and Lemma 1, that $s\left(q_{\max }\right)<s\left(q_{m+1}^{*}\right)<s\left(q_{k+1}^{*}\right)<s(1)$. The selection principle then guarantees that the desired conclusion in part (a) holds. Similarly, the conditional statement in part (b) implies that $s(1)<s\left(q_{k+1}^{*}\right)<s\left(q_{m+1}^{*}\right)<s_{\max }$, thus the selection principle guarantees that the desired conclusion in part (b) holds. Q.E.D.

Lemma A.3. The rate of return $q_{t}^{*}$ lies in the interval $\left[q^{*}, q_{\max }\right]$ for each $t \geq 1$. In particular, if (22) holds as an equality, then $q_{t}^{*} \in\left\{q^{*}, q_{\max }\right\}$ for all $t \geq 1$; and if (22) holds as a strict inequality, then $q^{*} \leq q_{2 t-1}^{*}<q_{2 t+1}^{*}<1<q_{2 t+2}^{*}<q_{2 t}^{*}<q_{\max }$ for all $t \geq 1$.

Proof of Lemma A.3. If $q^{*} q_{\max }=1$, implying that $q^{*} s\left(q^{*}\right)=s\left(q_{\max }\right)$, then the sequence $\left(q_{t}^{*}\right)$ cycles back and forth between $q^{*}$ and $q_{\max }$ in a simple period-2 orbit starting with $q_{1}^{*}=q^{*}$. To see this, note by Eq. (20) that, if $q_{t}=q_{\max }$ in some period $t$, then the equilibrium savings level for period $t+1$ is $q_{\max }\left(q_{\max }\right)=s_{\max }$, a savings level that is uniquely supported by the share rate of return $q^{*}$. Conversely, if $q_{t}^{*}=q^{*}$ in some period $t$, then the equilibrium savings level for period $t+1$ is $q^{*} s\left(q^{*}\right)=s\left(q_{\max }\right)$. The rates of return $q_{t}$ thus cycle back and forth between $q^{*}$ and $q_{\max }$.

Suppose, instead, that $q^{*} q_{\max }>1$, implying that $q^{*} s\left(q^{*}\right)>s\left(q_{\max }\right)$. By construction, $c^{\circ}\left(q_{1}^{*}\right)<\bar{c}^{\mathrm{o}}$; and all savings levels greater than $s(q)$ are supported by rates of return that are strictly smaller than $q$, for all $s(q) \geq s\left(q_{\max }\right)$. Also, from Eq. (20), one has the goods market clearing condition $c^{\mathrm{o}}\left(q_{t}^{*}\right)+c^{\mathrm{y}}\left(q_{t+1}^{*}\right)=w^{\mathrm{y}}+w^{\mathrm{o}}$ for every $t \geq 1$. In particular, the golden rule consumption profile satisfies this condition, implying that $\bar{c}^{\mathrm{y}}+\bar{c}^{\mathrm{o}}=w^{\mathrm{y}}+w^{\mathrm{o}}$. It then follows from $s\left(q_{\max }\right)<q_{1}^{*} s\left(q_{1}^{*}\right)=s\left(q_{2}^{*}\right)$ that $q_{2}^{*}<q_{\max }$. And $c^{\mathrm{o}}\left(q_{1}^{*}\right)+c^{\mathrm{y}}\left(q_{2}^{*}\right)=w^{\mathrm{y}}+w^{\mathrm{o}}$, with $c^{\mathrm{o}}\left(q_{1}^{*}\right)<\bar{c}^{\mathrm{o}}$, implies that $c^{\mathrm{y}}\left(q_{2}^{*}\right)>\bar{c}^{\mathrm{y}}=c^{\mathrm{y}}(1)$; hence $q_{2}^{*}>1$, for otherwise the selection principle used in the construction of $\left(q_{t}^{*}\right)$ is violated. Thus, $q_{1}^{*}<1<q_{2}^{*}<q_{\max }$. To complete the proof, it suffices to show that $q_{1}^{*}<q_{3}^{*}<1$; for then, using Lemma 2, it follows by a simple induction proof that $q^{*} \leq q_{2 t-1}^{*}<q_{2 t+1}^{*}<1<q_{2 t+2}^{*}<q_{2 t}^{*}<q_{\max }$ for all $t \geq 1$.

By assumption, $c^{\mathrm{o}}(q)=w^{\mathrm{o}}+q s(q)$ is a strictly increasing function of $q$ for all $q \geq \operatorname{MRS}\left(w^{\mathrm{y}}, w^{\mathrm{o}}\right)$. Together with (20), and the earlier finding that $q_{2}^{*}>1$, this implies that $s\left(q_{3}^{*}\right)=q_{2}^{*} s\left(q_{2}^{*}\right)>s(1)$. But, by the restrictions on the offer curve, all 
savings levels greater than $s(1)$ are supported by rates of return less than 1 ; cf. Fig. 2. In particular, then, $q_{3}^{*}<1$. Moreover, the selection principle guarantees that $q_{3}^{*} \geq q_{1}^{*} \equiv q^{*}$. If $q_{3}^{*}=q_{1}^{*}$, then $s\left(q_{3}^{*}\right)=s\left(q^{*}\right)=s_{\max }=q_{\max } s\left(q_{\max }\right)$. But this leads to a contradiction; for it holds by (20) that $s\left(q_{3}^{*}\right)=q_{2}^{*} s\left(q_{2}^{*}\right)$, and it has been established above that $q_{2}^{*}<q_{\max }$, hence $s\left(q_{3}^{*}\right)<s_{\max }$. It follows that $q_{3}^{*}$ must be strictly greater than $q_{1}^{*}$. Q.E.D.

By Lemma A.3, the savings and rate of return sequences $\left(s_{t}^{*}\right)$ and $\left(q_{t}^{*}\right)$ constitute a feasible real outcome for the Corporate Economy. For the reasons explained in the main text, under the hypotheses of Proposition 6.6 any Corporate Economy equilibrium must support these sequences. Moreover, it is straightforward if tedious to show that infinitely many Corporate Economy equilibria can be constructed to support these sequences; see Pingle and Tesfatsion (1996, Appendix). Q.E.D.

Proof of Proposition 6.9. The proof of case (a) follows from Lemmas A.2 and A.3, established in the course of proving Proposition 6.8.

Suppose (22) holds as a strict inequality. It then follows from Lemma A.3 that the subsequence $\left(q_{2 t-1}^{*}: t \geq 1\right)$ is strictly increasing in $t$ over the subinterval $\left[q^{*}, 1\right]$ and the subsequence $\left(q_{2 t}^{*}: t \geq 1\right)$ is strictly decreasing in $t$ over the subinterval $\left[1, q_{\max }\right]$. It follows by the monotone convergence theorem that these subsequences must converge to elements in these subintervals, say $q_{\mathrm{L}} \in\left[q^{*}, 1\right]$ and $q_{\mathrm{U}} \in\left[1, q_{\max }\right]$, respectively. If $q_{\mathrm{L}}=q_{\mathrm{U}}=1$, then $q_{t}^{*}$ converges cyclically to the golden rule rate of return $\bar{q}=1$. Suppose $q_{\mathrm{L}}<q_{\mathrm{U}}$, implying that the full sequence $\left(q_{t}^{*}\right)$ converges to a limit cycle supported by the period-2 orbit $\left\{q_{\mathrm{L}}, q_{\mathrm{U}}\right\}$ with either $q_{\mathrm{L}}<1$ or $1<q_{\mathrm{U}}$. In order for such a limit cycle to exist, it must hold by (20) that $s\left(q_{\mathrm{L}}\right)=q_{\mathrm{U}} s\left(q_{\mathrm{U}}\right)$ and $s\left(q_{\mathrm{U}}\right)=q_{\mathrm{L}} s\left(q_{\mathrm{L}}\right)$. But this implies that $s\left(q_{\mathrm{L}}\right)=q_{\mathrm{L}} q_{\mathrm{U}} \mathrm{s}\left(q_{\mathrm{L}}\right)$, which is only possible if $q_{\mathrm{L}} q_{\mathrm{U}}=1$ with $q_{\mathrm{L}}<1<q_{\mathrm{U}}$. Q.E.D.

\section{References}

Amel, D.F., Liang, J.N., 1992. A dynamic model of entry and performance in the U.S. banking industry. Discussion Paper 210, Finance and Economics Discussion Series, Federal Reserve Board, Washington, DC.

Azariadis, C., 1993. Intertemporal Macroeconomics. Blackwell Publishers, Cambridge, MA.

Balasko, Y., Shell, K., 1980. The overlapping generations model, I: the case of pure exchange without money. Journal of Economic Theory 23, 281-306.

Balasko, Y., Shell, K., 1981. The overlapping generations model, II: the case of pure exchange with money. Journal of Economic Theory 24, 112-142.

Barro, R., 1974. Are government bonds net wealth?. Journal of Political Economy 82, 1095-1117.

Bhattacharya, S., Thakor, A., 1993. Contemporary banking theory. Journal of Financial Intermediation 3, 2-50.

Bryant, J., 1981. Bank collapse and depression. Journal of Money Credit and Banking 13, 454-464. 
Cass, D., Yaari, M., 1966p. A re-examination of the pure consumption loan model. Journal of Political Economy 74, 353-367.

Champ, B., Freeman, S., 1994. Modelling Monetary Economies. Wiley, New York.

Diamond, P., 1965. National debt in a neoclassical growth model. American Economic Review 55, $1126-1150$.

Fama, E., 1985. What's different about banks? Journal of Monetary Economics 15, 29-39.

Gale, D., 1973. Pure exchange equilibrium of dynamic economic models. Journal of Economic Theory 6, 12-36.

Gertler, M., 1988. Financial structure and aggregate economic activity: an overview. Journal of Money, Credit, and Banking 20, 559-596.

Grandmont, J.M., Laroque, G., 1973. Money in the pure consumption loan model. Journal of Economic Theory 6, 382-395.

Grandmont, J.M., 1985. On endogenous competitive business cycles. Econometrica 53, 995-1045.

Hannan, T.M., Berger, A.N., 1991. The rigidity of prices: Evidence from the banking industry. American Economic Review 81, 938-945.

Kane, E., 1991p. The high cost of incompletely funding the FSLIC shortage of explicit capital. Journal of Economic Perspectives 3, 31-47.

Kaufman, G., 1992. The U.S. Financial System: Money, Markets, and Institutions. Prentice-Hall, Englewood Cliffs, NJ.

Lerner, A., 1959. Consumption-loan interest and money. Journal of Political Economy 67, 512-518 (plus Rejoinder, 523-525).

Malinvaud, E., 1953. Capital Accumulation and the efficient allocation of resources. Econometrica 21, 233-268.

Malinvaud, E., 1962. Efficient capital production: a corrigendum. Ibid. 30, 570-573.

McCallum, B.T., 1987. The optimal inflation rate in an overlapping-generations economy with land. In: Barnett, W.A., Singleton, K.J. (Eds.), New Approaches to Monetary Economics, Chapter 16. Cambridge University Press, New York, pp. 325-338.

Pingle, M., Tesfatsion, L., 1991. Overlapping generations, intermediation, and the first welfare theorem. Journal of Economic Behavior and Organization 15, 325-345.

Pingle, M., Tesfatsion, L., 1996. Active intermediation in a monetary overlapping generations Economy. ISU Economic Report No. 32 (revised October).

Pingle, M., Tesfatsion, L., 1997. Active intermediation in an overlapping generations economy with production and unsecured debt. ISU Economic Report No. 42 (revised May), Macroeconomic Dynamics, to appear.

Samuelson, P., 1958. An exact consumption-loan model of interest with or without the social contrivance of money. Journal of Political Economy 66, 467-482.

Shell, K., 1971. Notes on the Economics of Infinity. Journal of Political Economy 79, 1002-1011.

Tesfatsion, L., 1997. How economists can get alife. In: Arthur, W.B., Durlauf, S., Lane, D. (Eds.), The Economy as a Complex Evolving System, II, Santa Fe Institute Studies in the Sciences of Complexity, Proceedings Volume XXVII. Addison-Wesley, Reading, MA, pp. 533-564.

Thompson, E., 1967. Debt instruments in both macroeconomic theory and capital theory. American Economic Review 57, 1196-1210.

Tirole, J., 1985. Asset bubbles and overlapping generations. Econometrica 53, 1499-1528.

Williamson, S., 1992. Laissez-faire banking and circulating media of exchange. Working paper, Department of Economics, University of Western Ontario. 